\title{
The tarsal-metatarsal complex of caviomorph rodents: Anatomy and functional-adaptive analysis
}

\author{
Adriana M. Candela ${ }^{1}$ (1) | Nahuel A. Muñoz ${ }^{2}$ | César M. García-Esponda ${ }^{3}$
}

${ }^{1}$ CONICET, División Paleontología Vertebrados, Museo de La Plata, Paseo del Bosque, La Plata, B1900FWA, Argentina

${ }^{2}$ CONICET, División Paleontología Vertebrados, Museo de La Plata, Unidades de Investigación Anexo Museo, Facultad de Ciencias Naturales y Museo, Universidad Nacional de La Plata, Avenida 122 y 60, LA Plata, B1900FWA, Argentina

${ }^{3}$ Cátedra Zoología III Vertebrados, Facultad de Ciencias Naturales y Museo, Universidad Nacional de La Plata, Avenida 122 y 60, La Plata, B1900FWA, Argentina

\section{Correspondence}

Adriana M. Candela, Museo de La Plata, División Paleontología Vertebrados, Paseo del Bosque s/n, La Plata, Buenos Aires, Argentina 1900.

Email: acandela@fcnym.unlp.edu.ar

\begin{abstract}
Caviomorph rodents represent a major adaptive radiation of Neotropical mammals. They occupy a variety of ecological niches, which is also reflected in their wide array of locomotor behaviors. It is expected that this radiation would be mirrored by an equivalent disparity of tarsal-metatarsal morphology. Here, the tarsal-metatarsal complex of Erethizontidae, Cuniculidae, Dasyproctidae, Caviidae, Chinchillidae, Octodontidae, Ctenomyidae, and Echimyidae was examined, in order to evaluate its anatomical variation and functional-adaptive relevance in relation to locomotor behaviors. A qualitative study in functional morphology and a geometric morphometric analysis were performed. We recognized two distinct tarsal-metatarsal patterns that represent the extremes of anatomical variation in the foot. The first, typically present in arboreal species, is characterized by features that facilitate movements at different levels of the tarsal-metatarsal complex. The second pattern, typically present in cursorial caviomorphs, has a set of features that act to stabilize the joints, improve the interlocking of the tarsal bones, and restrict movements to the parasagittal plane. The morphological disparity recognized in this study seems to result from specific locomotor adaptations to climb, dig, run, jump and swim, as well as phylogenetic effects within and among the groups studies.
\end{abstract}

\section{KEYWORDS}

foot, geometric morphometrics, living, locomotion

\section{1 | INTRODUCTION}

Caviomorphs (or New Word Hystricognathi) constitute a monophyletic group of rodents (e.g., Fabre, Hautier, Dimitrov, \& Douzery, 2012; Fabre, Hautier, \& Douzery, 2015; Upham \& Patterson, 2015; Voloch, Vilela, Loss-Oliveira, \& Schrago, 2013), endemic to Central and South America. During their evolutionary history since the late Middle Eocene of Perú (Antoine et al., 2012), caviomorphs developed a noteworthy taxonomic richness that comprises about 250 extant species (e.g., Patton, Pardiñas, \& D'Elía, 2015; Woods \& Kilpatrick, 2005), which are usually grouped in four main clades (Erethizontoidea, Cavioidea, Octodontoidea and Chinchilloidea; e.g., Upham \& Patterson, 2015). Extant South American species belong to ten families: Erethizontidae (Neotropical porcupines or coendús), Abrocomidae (chinchilla rats and arboreal chinchilla rats), Echimyidae (spiny rats, bamboo rats, tree rats, coypus), Octodontidae (degus, rock rats, viscacha rats, coruros), Ctenomyidae (tuco-tucos), Caviidae (cavies, capybaras, Patagonian and Chacoan maras), Dasyproctidae (agoutis and acouchis), Cuniculidae (pacas), Chinchillidae (chinchillas, plain and mountain viscachas), and Dinomyidae (pacaranas; Ellerman, 1940; Patton et al., 2015; Woods \& Kilpatrick, 2005), constituting an important component of the Neotropical mammalian assemblages. Species richness of caviomorphs is accompanied by substantial ecological diversity, which is reflected in their wide array of locomotor behaviors (e.g., cursorials, jumpers, diggers, climbers, swimmers) and substrate preferences (from semiaquatic, terrestrial, fossorial, saxicolous, to scansorial and highly arboreal species). In addition, caviomorphs occupy a wide range of habitats and dwell in very diverse environments (e.g., rainforests, mountain forests, Atlantic forest, semideciduous forests, tropical savannas, Pampas, Monte and adjoining semiarid chaquenean areas, high Andean, and Puna; e.g., Mares \& Ojeda, 1982; Patton et al., 2015).

In view of their taxonomic richness, ecological diversity, and extended temporal and geographic range of distribution, living caviomorphs are the result of major adaptive radiation of Neotropical mammals. We hypothesize that this radiation is mirrored by an equivalent postcranial morphological disparity. However, despite the studies on 
the postcranium in fossil and living species (e.g., Candela, Rasia, \& Pérez, 2012; Candela \& Picasso, 2008; Elissamburu \& Vizcaíno, 2004; Ginot, Hautier, Marivaux, \& Vianey-Liaud, 2016; Hildebrand, 1978; Morgan, 2009; Morgan \& Verzi, 2011; Prochel, Begall, \& Burda, 2014; Rocha-Barbosa, Youlatos, Gasc, \& Renous, 2002, 2005; Samuels \& Van Valkenburgh, 2008), caviomorphs are not completely understood in terms of their locomotor adaptations.

Several contributions of the postcranium of mammals have recognized that the tarsal-metatarsal bones are informative from functional and phylogenetic points of view (e.g., Abello \& Candela, 2010; Argot, 2002; Candela \& Picasso, 2008; de Muizon, Cifelli, \& Bergqvist, 1998; Flores, 2009; Gebo, Dagosto, Beard, \& Qi, 2001; Gebo \& Dagosto, 1988; Ginot et al., 2016; Hildebrand, 1985a,b; Lewis, 1980a,b, 1989; Salton \& Szalay, 2004; Sargis, 2002; Szalay, 1994; Szalay \& Decker, 1974; Szalay \& Sargis, 2001, 2006; Weisbecker \& Schmid, 2007). The foot, perhaps because its direct contact with the substrate, is the part of the skeleton that supports some of the most complex loads of the body (Salton \& Szalay, 2004; Szalay, 1994; Szalay \& Sargis, 2001). Because this segment of the limb is a multi-bone system, small changes of its anatomy can reflect changes in its functional ability to support loads (Salton \& Szalay, 2004; Szalay, 1994; Szalay \& Sargis, 2001). Nevertheless, the foot anatomy of caviomorphs is one of the less studied regions of the postcranium, with only some of its tarsal-metatarsal structures analyzed (Candela \& Picasso, 2008; Candela et al., 2012; Ginot et al., 2016; Hildebrand, 1978; Weisbecker \& Schmid, 2007) from a functional-adaptive perspective. Moreover, comprehensive phylogenies of caviomorphs are rarely based on foot characters (Horovitz, Sánchez-Villagra, Martin, \& Aguilera, 2006).

Given the diverse locomotor behaviors and substrate preferences, we hypothesize that the tarsal-metatarsal anatomy of caviomorphs encompasses different morphological patterns with functional-adaptive value. Here, we examine the tarsal-metatarsal variation in caviomorphs and scrutinize the probable relationship between the foot features, its function, locomotor adaptations and substrate preferences. Consequently, we investigate if the adaptive radiation of the caviomorphs is reflected in their foot anatomy.

\section{2 | MATERIALS AND METHODS}

We examined the tarsal-metatarsal complex of at least one specimen of 35 species of caviomorphs (Table 1; Appendix). The morphological variation analyzed correspond to eight families belonging to all higher taxa (i.e., four superfamilies) nested in Caviomorpha (see Fabre, Hautier, Dimitrov, \& Douzery, 2012; Fabre, Hautier, \& Douzery, 2015; Upham \& Patterson, 2015; Voloch, Vilela, Loss-Oliveira, \& Schrago, 2013).

Anatomical features were studied from direct observation of the skeletons or from photographs. Diverse contributions on mammalian tarsal bone anatomy on different groups of mammals (e.g., Argot, 2002; Candela \& Picasso, 2008; de Muizon et al., 1998; Gebo \& Dagosto, 1988; Gebo et al., 2001; Ginot et al., 2016; Hildebrand, 1978; Lewis, 1980a,b, 1989; Salton \& Szalay, 2004; Sargis, 2002; Szalay,
1994; Szalay \& Decker, 1974; Szalay \& Sargis, 2001, 2006), provided an adequate standard of comparison for the analysis of the foot of caviomorphs. The osteological nomenclature used in this study follows that of Salton \& Szalay (2004) and Candela \& Picasso (2008). Nomenclature of the tarsal-metatarsal complex is illustrated in Figure $1 \mathrm{~A}$. The myological nomenclature and the muscular system information was that of McEvoy (1982) for erethizontids and García-Esponda \& Candela (2010, 2016) for cavioids.

Primary and secondary locomotor behaviors, as well as substrate preferences of the caviomorph taxa examined are listed in Table 1. Data on these ecological characteristics were taken from Nowak (1991), Lessa, Vassallo, Verzi, \& Mora (2008), Ojeda, Novillo, \& Ojeda (2015), and Patton et al. (2015). We considered the primary locomotor behavior as the principal mode employed by a species to move on the substrate, and secondary locomotor behaviors as those modes that were used less frequently by that species, e.g., to move on the substrate, to feed, to construct a den, or to evade predators. Data on secondary locomotor behavior were not available for many species. For example, the absence of information on this item in Myoprocta does not mean that the species of this genus do not occasionally dig or jump.

We scrutinized the anatomical variation within caviomorphs examined, and evaluated the possible functional relationships between tarsal-metatarsal anatomy and compatible movements of the foot, in association with the locomotor behavior and substrate preference in each case. On this basis, we test if, as in other mammals, morphology and function of the tarsus-metatarsus are distinctive within and between different clades of caviomorphs that show different locomotor habits.

Among tarsal bones, we placed focus on the morphological and functional relationships of the cuboid, navicular, tarsal sesamoids and cuneiforms. We also analyzed the morphological variation of the transverse tarsal joint (TTJ), i.e., the composite joint constituted by the calcaneocuboid (CCJ) and the astragalonavicular joints (ANJ; Figure 1A). We do not describe in details the anatomical characters of the astragalus and calcaneus, which were mainly studied in caviomorphs by Candela \& Picasso (2008) and Ginot et al. (2016), As our main objective was to explore the morphological variation of the tarsal-metatarsal complex between different groups of Caviomorpha, the emphasis was on intergeneric or higher taxonomic levels instead of intraspecific anatomical variation. Thus, in the text, all the species analyzed are almost always referred to by their generic names.

We performed a morphological study, a morphometric analyses with linear measurements, and a geometric morphometrics analysis. In the morphometric analysis we measured four variables (Figure 1B,C) on photographs using ImageJ 1.50i software (Schneider, Rasband, \& Eliceiri, 2012): navicular body length, plantar process of the navicular length, cuboid length, and third metatarsal length. We calculated two indices: (1) plantar process of the navicular length/navicular body length, and (2) third metatarsal length/ectocuneiform length, and created a box plot for each of them in R software 3.1.5 ( $R$ Development Core Team, 2015). 
TABLE 1 Main and secondary locomotor behaviors and substrate preferences of the caviomorph species examined in this study

\begin{tabular}{|c|c|c|c|}
\hline Taxon & Main locomotor behavior & Secondary locomotor behavior & Main substrate preference \\
\hline \multicolumn{4}{|l|}{ Erethizontoidea } \\
\hline \multicolumn{4}{|l|}{ Erethizontidae } \\
\hline Erethizon dorsatum & Climbing & Ambulatory & Scansorial \\
\hline Coendou prehensilis & Climbing & & Arboreal \\
\hline C. spinosus & Climbing & & Arboreal \\
\hline C. insidiosus & Climbing & & Arboreal \\
\hline Chaetomys subspinosus & Climbing & & Arboreal \\
\hline \multicolumn{4}{|l|}{ Cavioidea } \\
\hline \multicolumn{4}{|l|}{ Cuniculidae } \\
\hline Cuniculus paca & Ambulatory & Swimming, digging & Terrestrial \\
\hline \multicolumn{4}{|l|}{ Dasyproctidae } \\
\hline Dasyprocta azarae & Cursorial & Jumping & Terrestrial \\
\hline Myoprocta acouchi & Cursorial & & Terrestrial \\
\hline \multicolumn{4}{|l|}{ Caviidae } \\
\hline \multicolumn{4}{|l|}{ Caviinae } \\
\hline Cavia aperea & Ambulatory & & Terrestrial \\
\hline Microcavia australis & Ambulatory & Digging, climbing & Terrestrial \\
\hline Galea leucoblephara & Ambulatory & & Terrestrial \\
\hline \multicolumn{4}{|l|}{ Dolichotinae } \\
\hline Dolichotis patagonum & Cursorial & Jumping, stotting & Terrestrial \\
\hline Pediolagus salinicola & Cursorial & Jumping & Terrestrial \\
\hline \multicolumn{4}{|l|}{ Hydrochoerinae } \\
\hline Hydrochoerus hydrochaeris & Swimming/ambulatory & & Semiaquatic \\
\hline
\end{tabular}

Chinchilloidea

Chinchillidae

Chinchillinae

Chinchilla sp.

Lagidium viscacia

Lagostominae

Lagostomus maximus

\section{Octodontoidea}

Octodontidae

Octomys mimax

Octodontomys gliroides

Tympanoctomys aureus

T. kirchnerorum

Ctenomyidae

Ctenomys magellanicus

C. talarum

C. australis

Echimyidae

Myocastor coypus

Phyllomys pattoni.

Makalata didelphoides

Proechimys guairae

P. steerei

Trinomys dimidiatus

Euryzygomatomys spinosus

Clyomys laticeps

Lonchothrix emiliae

Dactylomys dactylinus

Kannabateomys amblionyx

Olallamys albicaudata
Jumping

Jumping

Ambulatory

Ambulatory
Ambulatory
Digging
Digging
Digging
Digging
Digging
Swimming
Climbing
Climbing
Ambulatory
Ambulatory
Ambulatory
Digging
Digging
Climbing
Climbing
Climbing
Undescribed

Saxicolous

Saxicolous

Digging, jumping

Terrestrial

Terrestrial

Digging

Digging, climbing

Saxicolous

Terrestrial

Fossorial

Fossorial

Terrestrial

Subterranean

Subterranean

Subterranean

Semiaquatic

Arboreal

Arboreal

Terrestrial

Terrestrial

Terrestrial

Semifossorial

Semifossorial

Arboreal

Arboreal

Arboreal

Undescribed

Data taken from Nowak (1991); Lessa et al., (2008); Ojeda et al., (2015); and Patton et al., (2015).

The geometric morphometric analysis was based on photographs of the tarsus-metatarsus in dorsal view. In these photographs, the specimens were placed with the lateromedial and proximodistal axes of the pes parallel to the camera lens. To minimize deformation due to the lens, only the central area of the photograph was considered. Fifteen homologous landmarks were chosen to represent the relative size and position of each tarsal bone in the configuration, as well as the degree of elongation and relative orientation of the astragalar neck. To 


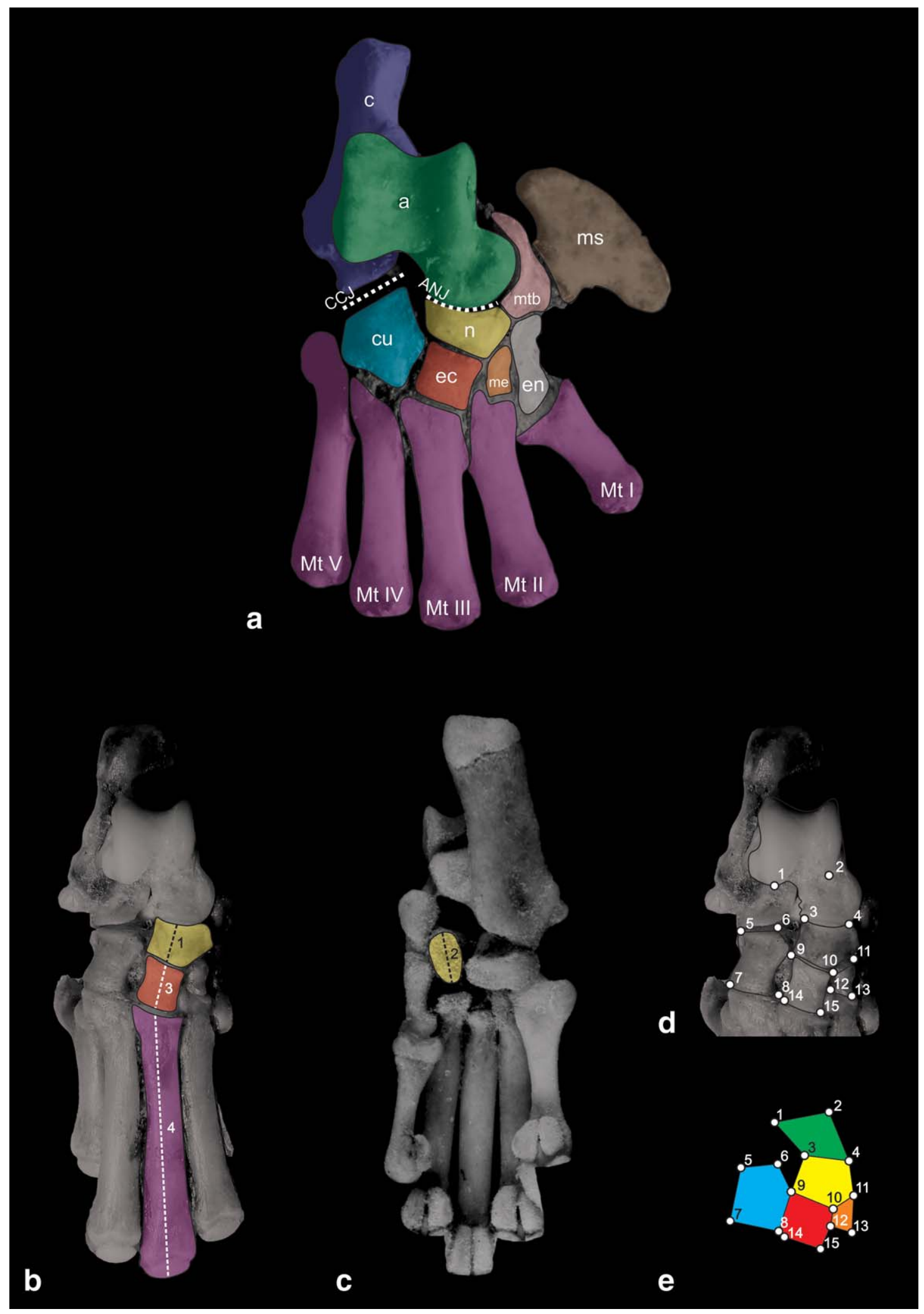

FIGURE 1 (A) nomenclature of the bones and main joints of the tarsal-metatarsal complex; (B and C) measurements used in the construction of indices; (D) landmarks used in the geometric morphometric analysis (landmark definitions are included in Table 2). (E) Landmarks and schematic used in Figures 7 and 8 to show shape changes on the PCA. a: astragalus (green); ANJ, astragalonavicular joint; c, calcaneus (blue); CCJ, calcaneocuboid joint; cu, cuboid (light blue), ec, ectocuneiform (red); en, entocuneiform (grey); me, mesocuneiform (orange); mtb, medial tarsal bone (pink), ms, medial sesamoid (brown); Mt I-V, first to fifth metatarsals (violet); n, navicular (yellow). Measurements: 1 , navicular body length; 2, plantar process of the navicular length; 3, cuboid length, and 4, third metatarsal length 
TABLE 2 Definitions of the digitized landmarks

\begin{tabular}{|c|c|}
\hline Landmark & Definition \\
\hline 1 & $\begin{array}{l}\text { Most distal point of the lateral lip of the astragalar } \\
\text { trochlea }\end{array}$ \\
\hline 2 & $\begin{array}{l}\text { Most distal point of the medial lip of the astragalar } \\
\text { trochlea }\end{array}$ \\
\hline 3 & $\begin{array}{l}\text { Most lateral contact point between the astragalus } \\
\text { and the navicular }\end{array}$ \\
\hline 4 & $\begin{array}{l}\text { Most medial contact point between the astragalus } \\
\text { and the navicular }\end{array}$ \\
\hline 5 & $\begin{array}{l}\text { Most lateral contact point between the calcaneus } \\
\text { and the cuboid }\end{array}$ \\
\hline 6 & $\begin{array}{l}\text { Most medial contact point between the calcaneus } \\
\text { and the cuboid }\end{array}$ \\
\hline 7 & Most laterodistal point of the cuboid \\
\hline 8 & $\begin{array}{l}\text { Most distal contact point between the cuboid and the } \\
\text { ectocuneiform }\end{array}$ \\
\hline 9 & $\begin{array}{l}\text { Contact point between the navicular, the cuboid and } \\
\text { the ectocuneiform }\end{array}$ \\
\hline 10 & $\begin{array}{l}\text { Contact point between the navicular, the } \\
\text { ectocuneiform and the mesocuneiform }\end{array}$ \\
\hline 11 & $\begin{array}{l}\text { Most medial contact point between the navicular and } \\
\text { the mesocuneiform }\end{array}$ \\
\hline 12 & $\begin{array}{l}\text { Most distal contact point between the ectocuneiform } \\
\text { and the mesocuneiform }\end{array}$ \\
\hline 13 & Most mediodistal point of the mesocuneiform \\
\hline 14 & Most laterodistal point of the ectocuneiform \\
\hline 15 & Most mediodistal point of the ectocuneiform \\
\hline
\end{tabular}

minimize digitation error, these landmarks were digitized by one of us (NAM) and the images were randomized. The landmarks used are shown in Figure 1D-E and their definitions are in Table 2. It has to be noted that the tarsus is not a rigid structure, as it is composed by several bones; for that reason, tarsi with a visible level of torsion or bending were discarded and only those with a straight arrangement were utilized. In addition, complete foot skeletons are scarcely represented in museum collections, and some of the specimens are incompletely cleaned, so that dried tissues do not allow to take some measurements; thus, a few other specimens were not included in the morphometric analyses.

A TPS file was created from a directory with the photograph files in tpsUtil and digitized in tpsDig2 (Rohlf, 2015).The landmark configurations were superimposed to remove the variation that does not correspond to shape. The superimposition was obtained by rotating, translating and scaling the configurations using a Generalized Procrustes Analysis (GPA; Rohlf, 1990). To analyze the shape variation, a Principal Components Analysis (PCA) was used (Manly, 1994). To evaluate the patterns of shape change, the principal component scores were related with the taxonomic and ecological information. The Generalized Procrustes Analysis and PCA were performed with MorphoJ 1.06d (Klingenberg, 2011), and for the visualization of intermediate morphologies TpsRelw (Rohlf, 2015) was used.

\section{3 | RESULTS}

\section{1 | Linear Morphometrics}

The analysis of the plantar process of the navicular length/navicular body length index (Figure 2A) indicates that chinchilloids, octodontoids, and eretizontoids have a relatively short plantar process of the navicular with respect to that of the cavioids. Among the latter group, Hydrochoerus exhibits the shortest plantar process while Pediolagus and Dolichotis the longest one.

Values of the third metatarsal length/ectocuneiform length index (Figure 2B) indicate that erethizontoids have relatively short metatarsals, octodontoids and cavioids show a great range of variation of this
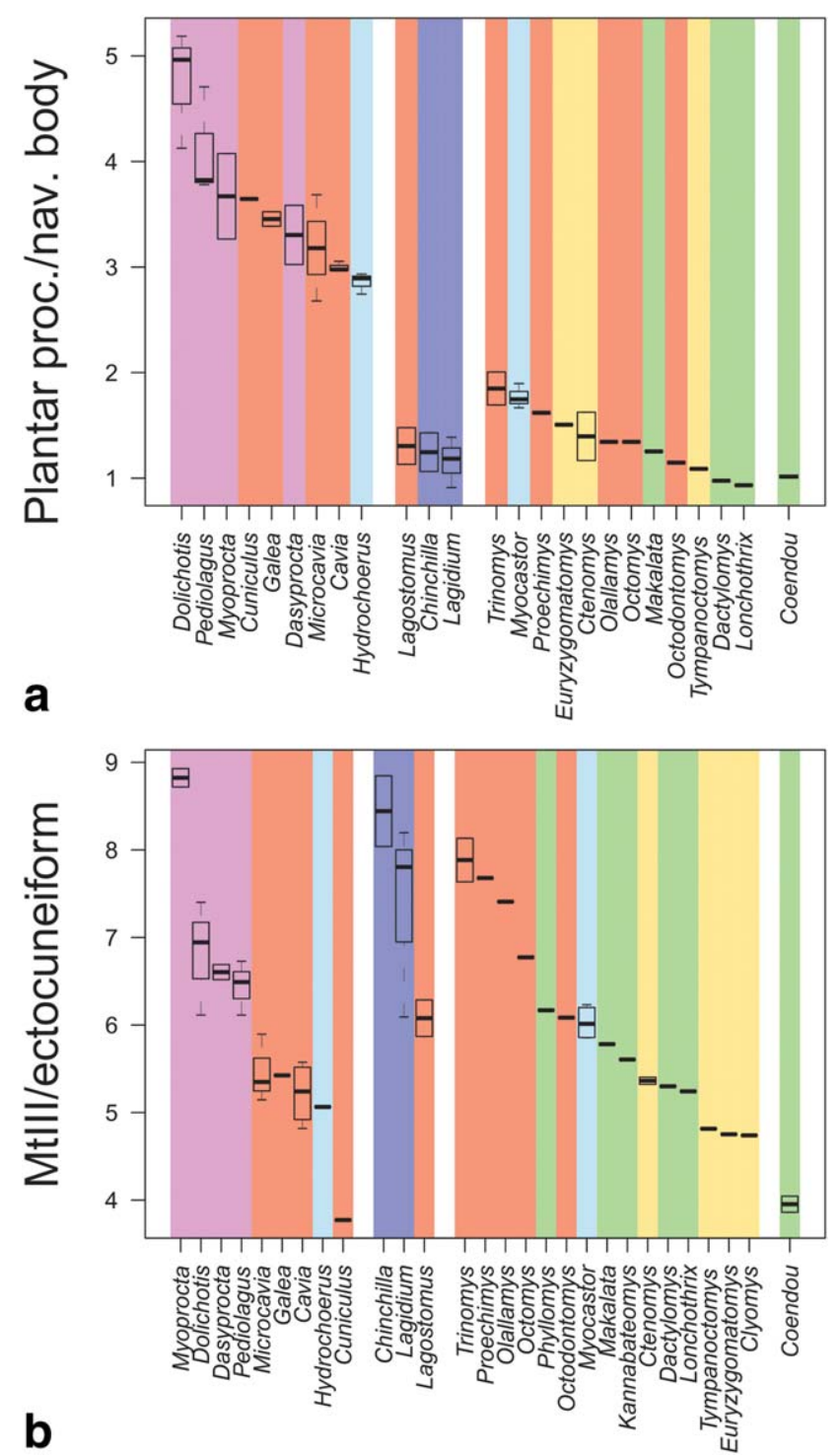

FIGURE 2 Box plots of morphological indices of the pes in caviomorph rodents. (A) Plantar process of the navicular length/ navicular body length index; (B) third metatarsal length/ ectocuneiform length index. Violet, cursorial; red, ambulatory; light blue, swimming; blue, jumping; green, climbing; yellow, digging.

Taxa are arranged by main clades (superfamilies) and then sorted in descending order by mean value 


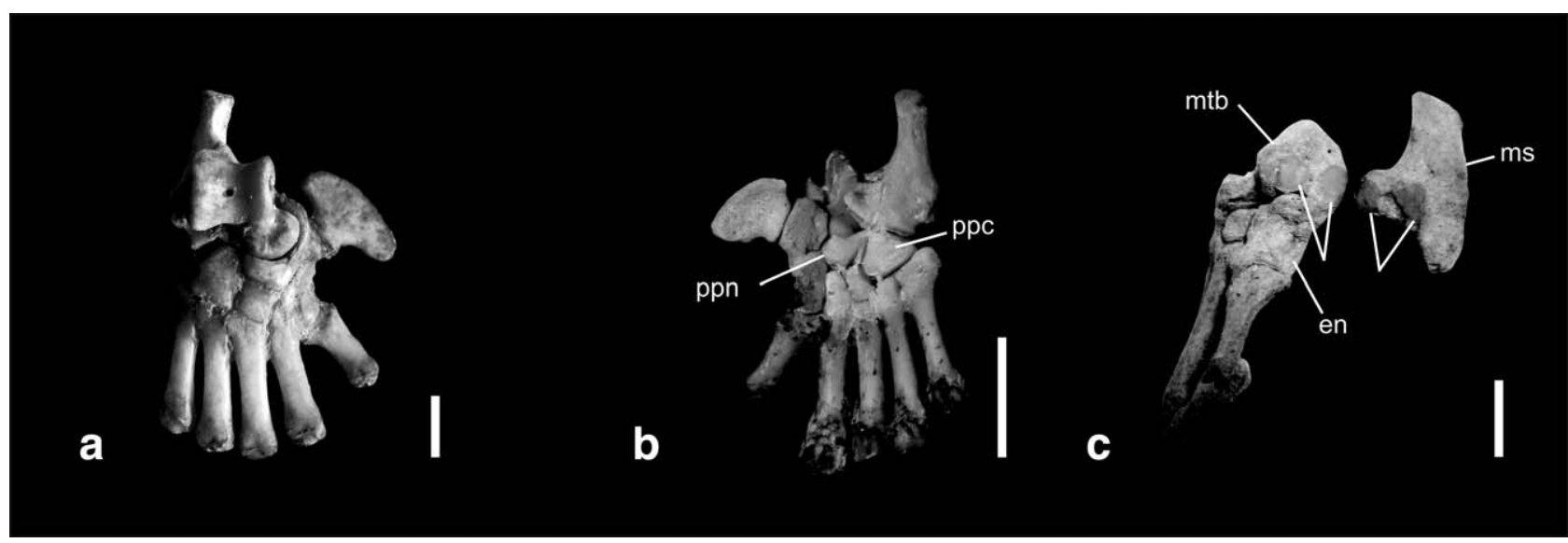

FIGURE 3 Tarsal-metatarsal complex of Erethizontidae showing detail of the articular surfaces of the medial tarsal bone and medial sesamoid (arrows). (A) Coendou prehensilis (MLP1086, mirrored), dorsal view; (B) C. spinosus (MPS-Z 185, mirrored), plantar view; (C) C. prehensilis (MN 4925, mirrored), medial view, Scale: $10 \mathrm{~mm}$. en, entocuneiform; mtb, medial tarsal bone, ms, medial sesamoid; ppc, plantar process of the cuboid; ppn, plantar process of the navicular. Arrows indicate articular surfaces of the mtb and ms

index, and chinchilloids show middle and high values. Among octodontoids, the metatarsals of digging and climbing species are relatively shorter than those of the ambulatory and swimming taxa. Among chinchillids, Chinchilla and Lagidium show the longest metatarsals. Among cavioids, the ambulatory taxa have the shortest metatarsals while the cursorial species have the longest (Cuniculus has the shortest metatarsals while Myoprocta has the longest).

\section{2 | The Tarsal-Metatarsal Complex in Caviomorphs: Anatomical Variation}

\subsection{1 | Erethizontoids}

The astragalus is mediolaterally extended (Figure 3). The astragalar head is large and medially oriented with respect to the proximo-distal axis of the foot. The astragalar neck is relatively short with respect to the astragalar length (Figure 3A). The navicular facet of the astragalar head is continued medially by a large and convex astragalomediotarsal facet for the medial tarsal bone (=first sesamoid), that spreads on the medial region of the astragalar head. The medial tarsal bone also articulates with the navicular and the entocuneiform, completely wrapping the astragalomediotarsal facet. The medial tarsal bone is wide and large compared with the navicular size. The medial sesamoid (=second sesamoid) is hypertrophied in Coendou and Chaetomys more than in E. dorsatum, and articulates with the medial tarsal bone through two well distinguished facets (Figure $3 \mathrm{C}$ ). The sustentaculum of the calcaneus is close to the calcaneocuboid facet, so that the distal portion of this bone is short. The latter feature is related with the position of the ANJ and the CCJ, which are located at the same level. The plantar process of the navicular is barely developed (Figures $2 \mathrm{~A}$ and $3 \mathrm{~B}$ ). The cuboid is larger than the ectocuneiform (Figure $3 \mathrm{~A}$ ), its plantar process is moderately developed (Figure 3B), and surrounds a shallow groove for the tendon of the peroneus longus muscle. The ectocuneiform is obliquely orientated (in a medioproximal-lateralodistal direction) with respect to the longitudinal axis of the Mt III. The entocuneiform is subrectangular in shape. This bone is at least twice as long as the mesocuneiform and extends distally beyond the level of the distal border of the ectocuneiform (Figure 3A,C).

The metatarsals are not close-packed and are relatively short when compared with the ectocuneiform length (Figure 2B); thus, the length of the Mt III is about four times that of the ectocuneiform. In Coendou and Chaetomys the $\mathrm{Mt} \mathrm{I}$ is more medially oriented than in E. dorsatum. The Mt V is slightly shorter than the Mt IV (Figure 3).

\subsection{2 | Chinchilloids}

In Chinchilla, Lagidium and Lagostomus the astragalus is longer than it is wide (Figure 4). The astragalar head is rather parasagittally oriented with respect to the astragalar body. The astragalar head is relatively small, compared with that of the erethizontids, and separated from the astragalar body by a relatively long neck. The navicular facet of the astragalar head is rounded and less lateromedially extended than in cavioids (see below). This facet is continued medioventrally by the astragalomediotarsal facet for the medial tarsal bone. The latter facet is located on the medial plantar portion of the astragalar head. The medial tarsal bone, although well developed, is relatively smaller than that of erethizontids. The calcaneocuboid facet of the calcaneus is distally located with respect to the sustentaculum, so that the distal portion of this bone is long. This feature expresses the distal location of the CCJ with respect to the ANJ. The plantar process of the navicular is distinctive but relatively short with respect to the navicular body (Figure $2 \mathrm{~A}$ ); it does not extend beyond the distal border of the cuboid (Figure 4). The cuboid is subequal (Lagidium and Chinchilla; Figure 4A,B) or smaller (Lagostomus; Figure 4C) than the ectocuneiform; its plantar process is markedly developed. The ectocuneiform is oriented in line with respect to the longitudinal axis of the Mt III. In Chinchilla and Lagidium the entocuneiform is elongate and narrow (the entocuneiform length is at least three times that of the mesocuneiform), extending beyond the distal border of the ectocuneiform and subequal in width to the mesocuneiform. In Lagostomus, the entocuneiform is somewhat smaller than in Lagidium and Chinchilla (Figure 4). The plantar aspect of the base of the Mt II possesses a large tubercle (Figure 4C) lateroproximally 


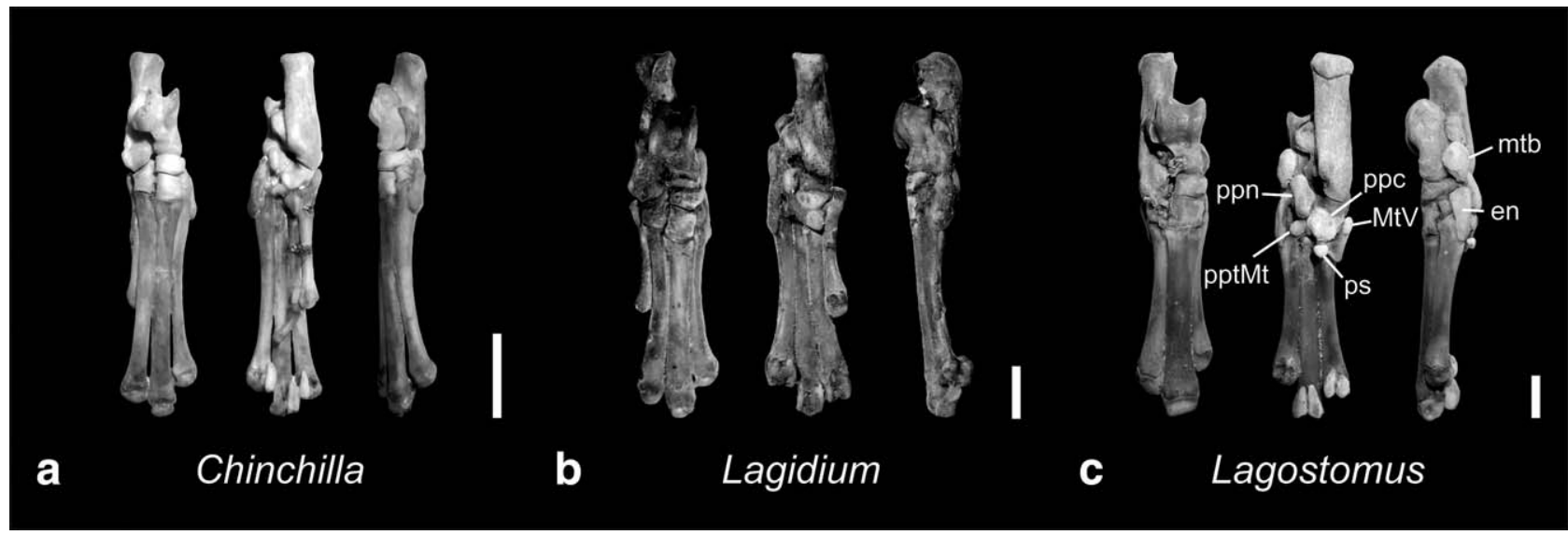

FIGURE 4 Tarsal-metatarsal complex of Chinchillidae in dorsal, ventral and plantar views. (A) Chinchilla sp. (MLP 31.XII.02.37, mirrored); (B) Lagidium viscacia (MLP 2021); (C) Lagostomus maximus (MPS-Z 200, mirrored). Scale: 10 mm. en, encontocuneiform; mtb, medial tarsa bone; ppc, plantar process of the cuboid; ppn, plantar process of the navicular; pptMtIl, plantar proximal tubercle of the MtIl; ps, plantar sesamoid; MtV, metatarsal V

oriented toward the plantar process of the cuboid. In all genera, there is a plantar sesamoid bone, located distally to the plantar face of the cuboid.

In Chinchilla and Lagidium, the metatarsals are relatively long with respect to the length of the ectocuneiform (Figure $2 \mathrm{~B}$ ), more than in Lagostomus. Mt I is absent in all three genera. In Chinchilla and Lagidium Mt $V$ is well developed (Figure 4A,B), extending about half the length of $\mathrm{Mt}$ III, whereas in Lagostomus, $\mathrm{Mt} \mathrm{V}$ is reduced to its proximal portion (Figure 4C). In all genera, the metatarsals are proximally closedpacked, but in Lagostomus the metatarsals are more strongly united at the distal ends.

\subsection{3 | Octodontoids}

In arboreal echimyids (Figure 5A), as well as in the semiaquatic Myocastor (Figure $5 \mathrm{E}$ ), the astragalar head resembles that of erethizontids in its medial displacement and relatively globular shape, although not to the degree observed in the porcupines (Figure 5). On the other hand, in the terrestrial Proechimys, Trinomys, and the semifossorial Euryzygomatomys and Clyomys (Figure 5C,D), the astragalar head is somewhat less medially oriented than that of the arboreal taxa. In some arboreal taxa (e.g., Dactylomys, Kannabateomys), there is a relatively large medial tarsal bone (Figure 5A) that articulates with the navicular, entocuneiform, and the astragalomediotarsal facet of the astragalar head. In Myocastor (Figure 5E) and the arboreal taxa (Figure 5A,B), the sustentaculum of the calcaneus is close to the calcaneocuboid facet, so that the distal portion of this bone is short, although not to the same degree as in erethizontids. Consequently, the ANJ and CCJ are located approximately at the same level. Conversely, the terrestrial Proechimys and Trinomys show a more elongated and narrow distal calcaneal portion than that of the arboreal equimyids. The plantar process of the navicular is short (Figure 2A), not extending beyond the distal border of the cuboid. The cuboid is relatively larger than or subequal to the ectocuneiform (Figure 5). The latter is obliquely oriented with respect to the longitudinal axis of the Mt III. In Proechimys, Euryzygomatomys, Clyomys and Myocastor the cuboid is relatively smaller than that of the arboreal forms (Figure
5C,E). In all echimyids, the entocuneiform is subrectangular in shape, extending distally beyond the level of the distal border of the ectocuneiform. The plantar process of the cuboid is moderately developed (Figure 5A,E).

The metatarsals of the terrestrial Trinomys and Proechimys are lengthened (Figure 2B), so that the $\mathrm{Mt}$ III is approximately eight times longer than the ectocuneiform. In Olallamys, the Mt III has a similar value to that of terrestrial echimyids. On the contrary, the arboreal Makalata, Lonchothrix, Phyllomys, Dactylomys and Kannabateomys show metatarsals relatively shorter (Figure 2B), but not as much as in erethizontids. In these genera, Mt III length is between five and six times the ectocuneiform length. In addition, the metatarsals of Trinomys and Proechimys are close-packed (Figure $5 \mathrm{C}$ ), especially at its proximal and medial portions, while in the arboreal echimyids the metatarsals are spread (Figure 5A,B). Myocastor has metatarsals longer than those of the arboreal echimyids, with the exception of Phyllomys (Figure 2B). In the semifossorial Clyomys and Euryzygomatomys, the metatarsals are even shorter than those of the arboreal forms.

In echimyids, the $\mathrm{Mt} \mathrm{I}$ is not medially orientated.The $\mathrm{Mt} I$ of the arboreal taxa is relatively longer than that of the terrestrial forms (more than half the length of the Mt III). In Trinomys and Proechimys the Mt I is approximately half the length of $\mathrm{Mt} \mathrm{III} \mathrm{(Figure} \mathrm{5C).} \mathrm{The} \mathrm{length} \mathrm{of} \mathrm{the}$ $\mathrm{Mt} \mathrm{V}$ of the echimyids examined is variable. In the arboreal Makalata, for example, the $\mathrm{Mt} \mathrm{V}$ is relatively long (more than half the length of Mt III), a similar condition to that observed in Phyllomys and Lonchotrix. In the terrestrial Proechimys (and in a lesser degree in Trinomys) the Mt $\mathrm{V}$ is relatively shorter than that of the arboreal genera. As in terrestrial echimyids, in the semifossorial Euryzygomatomys the Mt I and Mt $\mathrm{V}$ are relatively shorter than those of the arboreal taxa.

The Ctenomyidae Ctenomys (Figure 5F) shows several tarsal features similar to those of arboreal echimyids. In addition, this genus has robust metatarsals and the $\mathrm{Mt} \mathrm{V}$ relatively short with respect to $\mathrm{Mt}$ III.

Octodontidae (Figure 5G-I) have an elongated astragalus, a relatively long astragalar neck, and a narrow and elongated ectocuneiform. The cuboid is also elongated. The astragalar head is slightly medially 


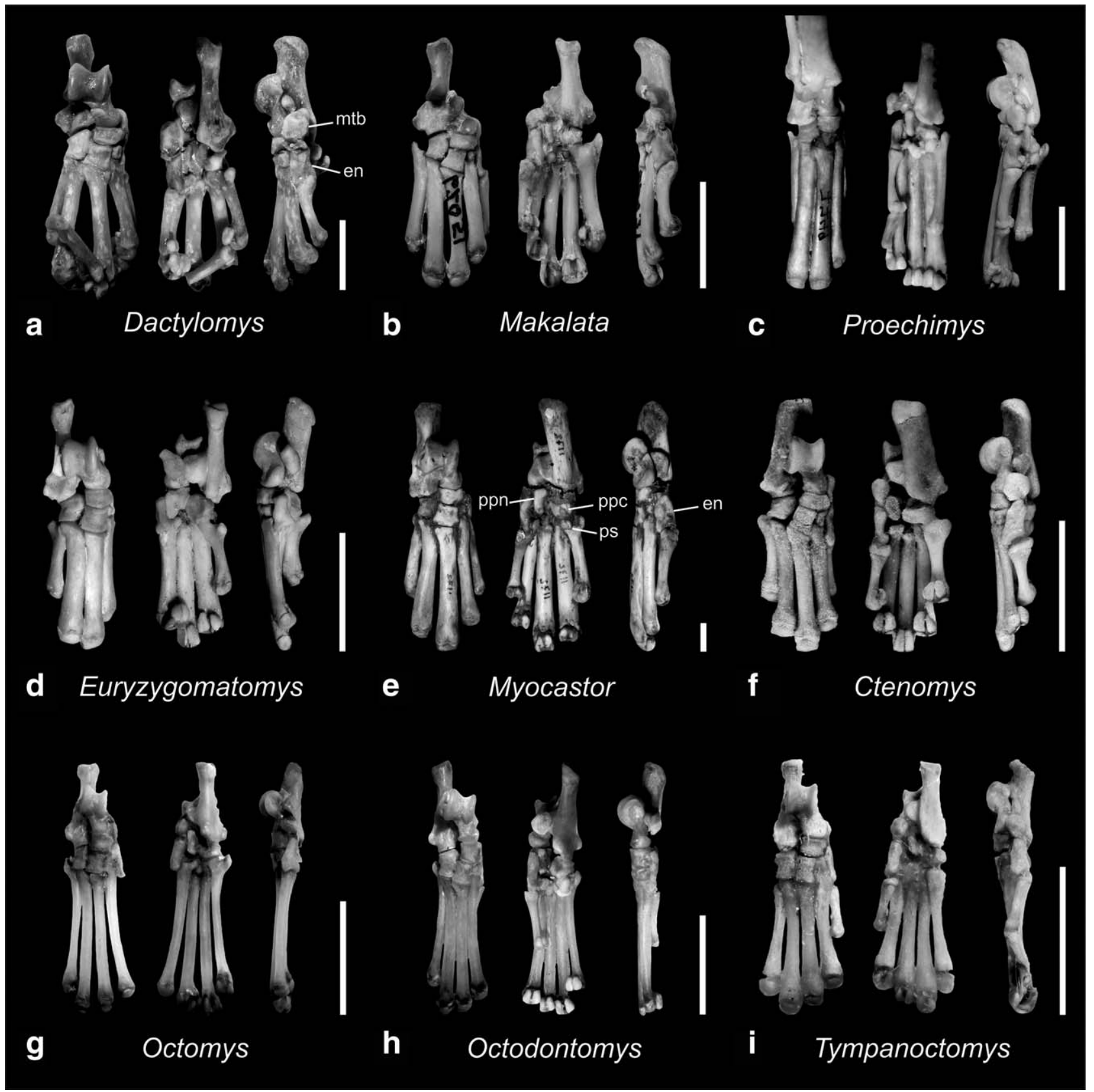

FIGURE 5 Tarsal-metatarsal complex of Octodontoidea in dorsal, plantar and medial views. (A) Dactylomys dactylinus (YPM 1391); (B) Makalata didelphoides (FMNH 62051; mirrored, lacking astragalus); (C) Proechimys guairae (MLP 22.II.00.7, mirrored); (D) Euryzygomatomys spinosus (MLP 16.VII.02.11, mtb displaced); (E) Myocastor coypus (MLP 1172, mirrored, mtb is lacking); (F) Ctenomys talarum (MLP 2507, mirrored); (G) Octomys mimax (IADIZA CM 03785, mirrored); (H) Octodontomys gliroides (MACN 25.197, mirrored); I, Tympanoctomys kirchnerorum (CNP 1819, mirrored). Scale: $10 \mathrm{~mm}$. en, entocuneiform; mtb, medial tarsal bone; ppc, plantar process of the cuboid; ppn, plantar process of the navicular; ps, plantar sesamoid

displaced with respect to the astragalar trochlea. The CCJ is somewhat distally located with respect the ANJ. The plantar process of the navicular (Figure 2A) does not extend beyond the distal border of the cuboid, and the ectocuneiform is less obliquely orientated with respect to the longitudinal axis of the Mt III than in Ctenomys.

There is certain variation on the relative length of the metatarsals (Figure 2B). Octodontomys and Octomys has elongated and gracile, whereas Tympanoctomys has shorter and more robust metatarsals (Fig- ure $2 \mathrm{~B})$. In these genera, the $\mathrm{Mt} \mathrm{V}$ is not as shortened as in terrestrial echimyids.

\subsection{4 | Cavioids}

Most cavioids share a particular set of foot features: astragalar head parasagittally oriented, lateromedially extended navicular facet of the astragalar head, well-developed plantar process of the navicular, relatively large ectocuneiform with respect to the cuboid, distal portion of 


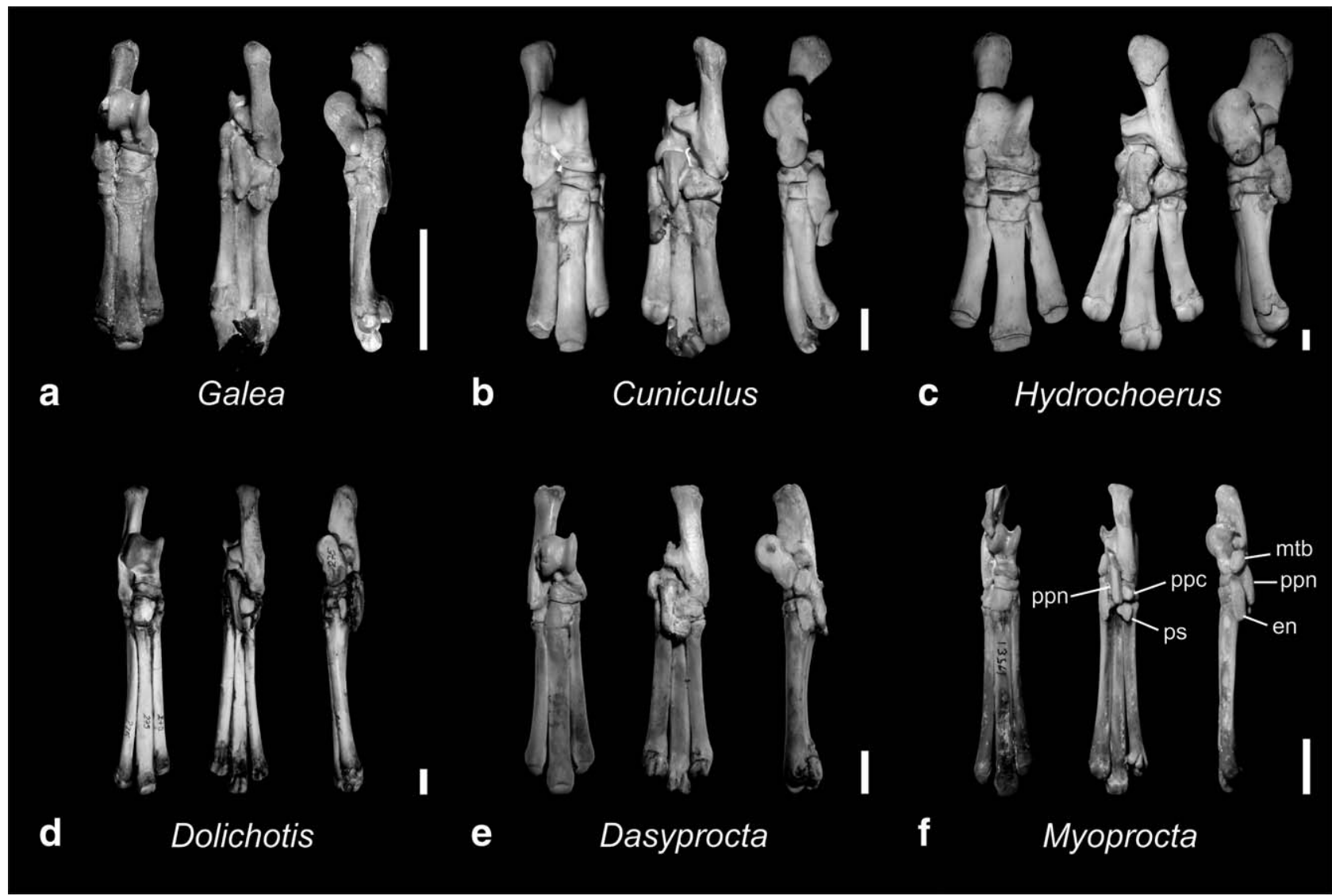

FIGURE 6 Tarsal-metatarsal complex of Cavioidea in dorsal, ventral, and medial views. (A) Galea leucoblephara (MLP 1928, mirrored); (B) Cuniculus paca (MACN-Ma 49.396, mirrored, ps and mtb, MtV are lacking); (C) Hydrochoerus hydrochaeris (MACN 43.43, mtb, en, ps, MtV are lacking); (D) Dolichotis patagonum (MLP 275, mtb is lacking); (E) Dasyprocta azarae (CNP 790, mirrored); (F) Myoprocta acouchi (YPM 1360). Scale: $10 \mathrm{~mm}$. en, entocuneiform; mtb, medial tarsal bone; ppc, plantar process of the cuboid; ppn, plantar process of the navicular; ps, plantar sesamoid

the calcaneus elongated, reduced medial tarsal bone, elongated metatarsals, absence or marked reduction of $\mathrm{Mt} \mathrm{I}$ and $\mathrm{Mt} \mathrm{V}$ (Figure 6).

The astragalus is longer than it is wide, but shows certain variability. In Hydrocherous, it is wider than in the other genera, being almost as wide as long (Figure 6C); it is relatively more elongated in Cuniculus (Figure 6B), and markedly long in the dasyproctids Dasyprocta and Myoprocta, and in the caviids Dolichotis and Pediolagus (Figure 6D,F). The astragalar neck is relatively short in Hydrochoerus and caviines (Figure $6 \mathrm{~A}, \mathrm{C}$ ); dasyproctids show the longest astragalar necks. The astragalomediotarsal facet for the medial tarsal bone is narrow and ventrally located on the medial region of the astragalar head. This feature is in association with the small size of the medial tarsal bone.

The CCJ is distally located with respect to the ANJ (a feature related to the elongated distal region of the calcaneus). In most cavioids, the plantar process of the navicular is keel-shaped and highly developed, extending both proximal and distally, largely overpassing the distal border of the cuboid. In Cuniculus this process is robust, but it slightly overpasses the distal border of the cuboid. In Hydrochoerus it is very wide and just overpasses the distal border of the cuboid. Pediolagus and Dolichotis have the longest navicular process (Figure 2A). The cuboid has a well-developed groove for the tendon of the peroneus longus muscle. In most cavioids, the ectocuneiform is orientated parallel or slightly oblique with respect to the longitudinal axis of the Mt III. In Cuniculus, the entocuneiform is well developed, whereas it is small in the other cavioids, a feature associated with the absence of the digit I. The major reduction of the entocuneiform is seen in dasyproctids and dolichotines, in which this bone is scale-shaped with a small or absent contact with the medial tarsal bone (Figure 6D,F). In Dolichotis and Pediolagus, the medial tarsal is also reduced. In all cavioid genera, there is a well-developed plantar sesamoid bone that is located distally to the plantar face of the cuboid.

The metatarsals are relatively elongated (more than six times the ectocuneiform length; Figure 2B). The semiaquatic Hydrochoerus shows relatively shorter metatarsals compared with the others cavioids. Among terrestrial forms, Cuniculus shows the shortest metatarsals. In this taxon, the entocuneiform articulates with a complete but short Mt I-digit I; the Mt V is short and robust, and the digit $\mathrm{V}$ is small. The remaining cavioids lack $\mathrm{Mt} \mathrm{I}$. Mt V is vestigial in Hydrochoerus and much reduced in Dasyproctidae, Caviinae and Dolichotinae. In Caviidae (with exception of Hydrochoerus) and Dasyproctidae, Mt II, III and IV are close-packed. 
TABLE 3 First eight principal components

\begin{tabular}{|llll|}
\hline PC & Eigenvalues & \% Var. & Cum. Var. \% \\
\hline 1 & 0.00919349 & 42,306 & 42,306 \\
\hline 2 & 0.00534452 & 24,594 & 66,900 \\
\hline 3 & 0.00135452 & 6,233 & 73,134 \\
\hline 4 & 0.00120173 & 5,530 & 78,664 \\
\hline 5 & 0.00077879 & 3,584 & 82,247 \\
\hline 6 & 0.00066905 & 3,079 & 85,326 \\
\hline 7 & 0.00052586 & 2,420 & 87,746 \\
\hline 8 & 0.00049783 & 2,291 & 90,037 \\
\hline
\end{tabular}

PC, principal component; \% Var., percent of variance explained by each PC; Cum. Var. \%, Cumulative variance percent.

\section{3 | Geometric Morphometrics}

The first eight principal components of the PCA account for 90\% of cumulative variance; as observed in Table 3, after PC2 there is little explained variation by each PC. Principal component 1 (PC1) and Principal component 2 (PC2; Figure 7) account for $\sim 67 \%$ of cumulative variance. On PC1 ( 42\%) there is a variation from a tarsus relatively wide, a relatively large cuboid, wide ectocuneiform, calcaneocuboid joint at the same level as the astragalonavicular joint and a medially oriented astragalar head in negative values, to a relatively narrow tarsus, a relatively small cuboid, narrow ectocuneiform, CCJ distally located with respect to the ANJ and more parasagittally oriented astragalar head in positive values. On PC2 ( 24\%) there is a variation from a large cuboid, relatively small ectocuneiform, and long navicular and astragalar neck on negative values, to a small cuboid, large ectocuneiform, and short navicular and astragalar neck (Figure 7).

Figure $8 \mathrm{~A}$ shows the same PCA, but emphasizing the visualization of the superfamilies. The obtained grouping seems to be indicative of a strong taxonomic influence: the Erethizontoidea occur in the negative values of PC1 and extreme negative values of PC2, the Octodontoidea occur principally in the negative values of $\mathrm{PC} 2$, the Cavioidea occur principally in the positive values of PC2, and the Chinchilloidea occur in middle-positive values of PC1 and negative values of PC2. There is a gradient of variation shared by the Cavioidea and the Octodontoidea (principally in PC1 but also in PC2), from lower PC1 and higher PC2 values to higher PC1 and lower PC2 values. In the case of the Octodontoidea, the change goes from the Echimyidae to the Octodontidae,
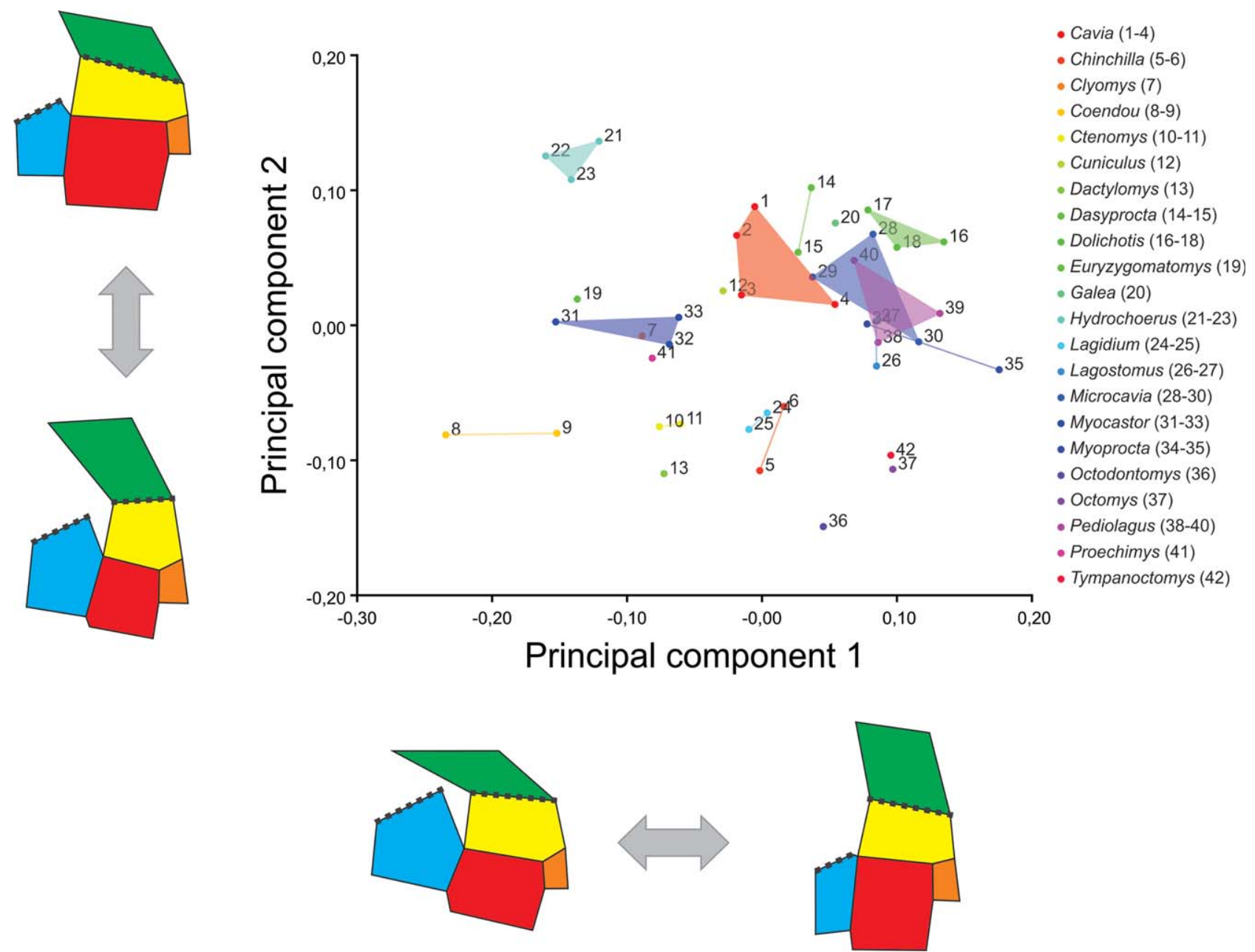

FIGURE 7 Shape variation of the tarsus of caviomorphs in the morphospace defined by the first two PCs 

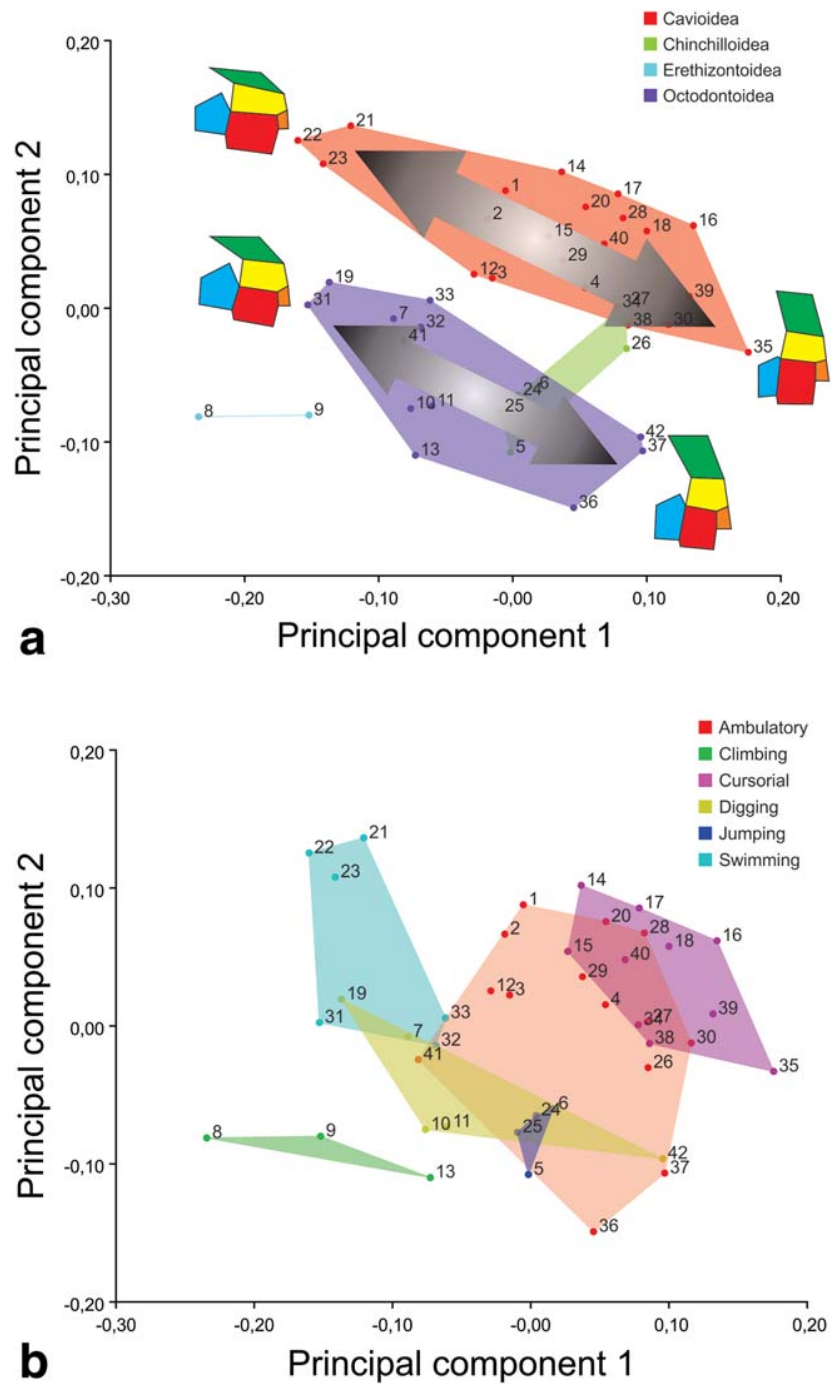

FIGURE 8 Shape variation of the tarsus of caviomorphs in relation to taxonomy and ecology. (A) Same PCA from Figure 7, showing the superfamilies, with special emphasis in the parallelism between Cavioidea and Octodontoidea; (B) same PCA from Figure 7, showing the main locomotor specializations (climbing, swimming, cursorial, digging, jumping, ambulatory)

and in the case of Cavioidea goes from Hydrochoerus to the remaining cavioids (with Cuniculus in the middle). The principal difference between the two superfamilies (shown mostly in PC2) seems to be a more robust configuration, a more distal located calcaneocuboid joint, and a relatively smaller cuboid in the Cavioidea.

The Chinchilloidea present two strikingly different morphologies, with Chinchilla and Lagidium sharing the morphospace with the Octodontoidea and Lagostomus closer to the Cavioidea.

In the Figure 8B, the main locomotor specializations are plotted over the same PCA. Climbers display negative values of PC1 and PC2, swimmers have negative values of PC1 and mid-positive values of PC2, cursorial taxa have positive values of PC1 and PC2, diggers have mainly negative values of PC2, jumpers have mid values of PC1 and negative values of PC2, and the ambulatory species have mostly positive values for both PC1 and PC2.

\section{DISCUSSION}

\section{1 | Identifying Tarsal-Metatarsal Patterns}

Two distinct tarsal-metatarsal patterns representing the extremes of the observed anatomical variation are recognized in caviomorphs: one is typically present in erethizontids and arboreal echimyids (tarsal-metatarsal pattern I; Figure 9A,B), while the other is characteristic of the most specialized cursorial cavioids (tarsal-metatarsal pattern II; Figure9 C,D). From a functional-adaptive point of view, these patterns seem to contrast climbing versus cursorial modes of locomotion, although intermediate conditions were also identified.

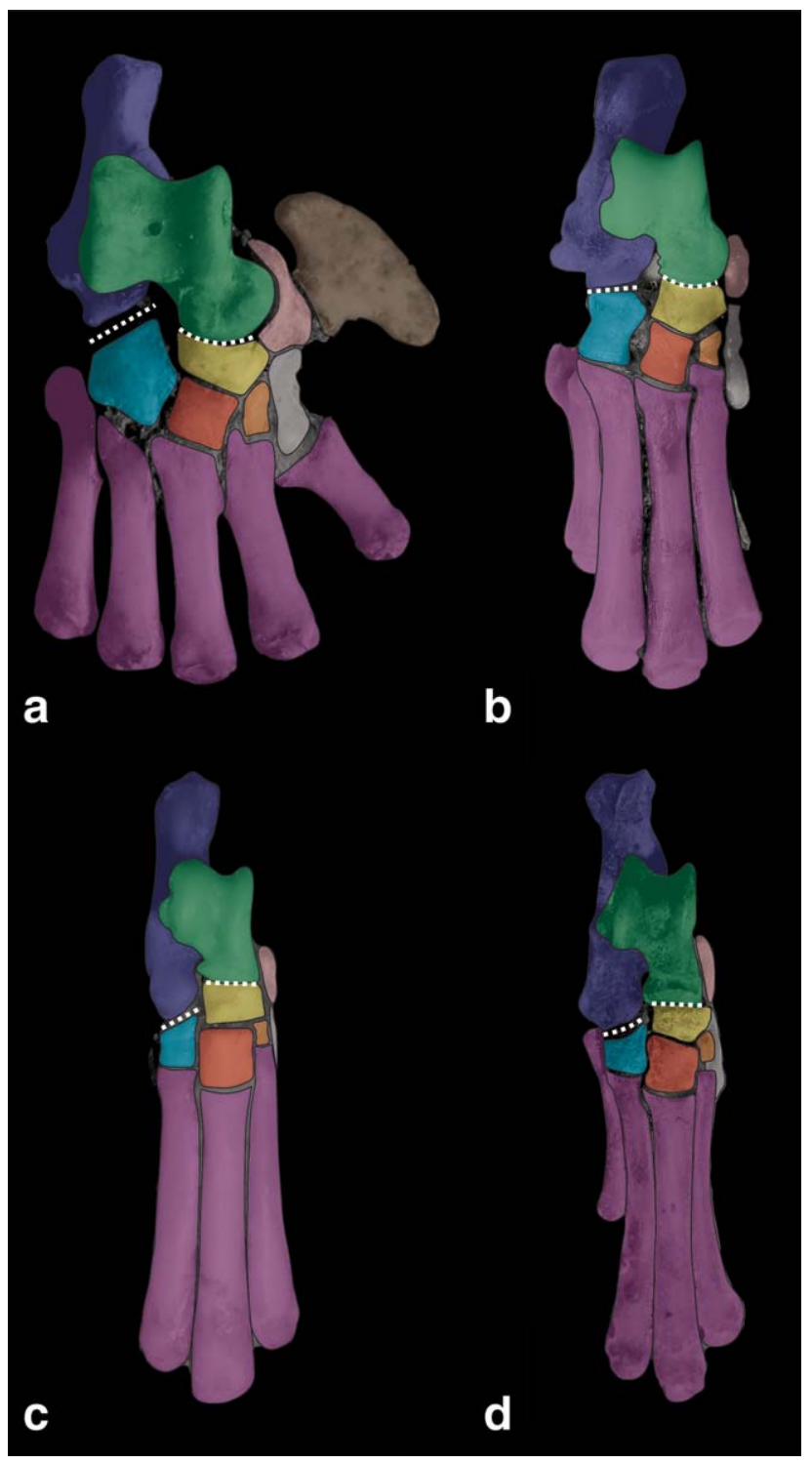

FIGURE 9 Tarsal-metatarsal complex represented in the four superfamilies of caviomorphs. (A and B) Tarsal-metatarsal Pattern I (TMPI); (C and D) tarsal-metatarsal Pattern II (TMPII). (A) Erethizontoidea (Coendou); (B) Octodontoidea (Ctenomys); (C) Cavioidea (Cavia); (D) Chinchilloidea (Lagidium). Colours indicate the same bones as those of the figure 1 . Scale: $10 \mathrm{~mm}$ 


\subsection{1 | Tarsal-Metatarsal Pattern I (TMPI)}

In this pattern (Figure 9A,B) the tarsus is relatively wide with respect to its length. The astragalar body is wide; the astragalar head is large and medially oriented with respect to the astragalar trochlea, and the astragalar neck is relatively short. The CCJ is located at the same level as the ANJ, resulting in a slightly curve TTJ. The medial tarsal bone is large, articulating with the medially extended and large astragalomediotarsal facet of the astragalar head. The plantar process of the navicular is scarcely developed. The cuboid is larger than the ectocuneiform. The latter bone is obliquely orientated with respect to the longitudinal axis of Mt III. The entocuneiform is relatively large, subrectangular, and wider than the mesocuneiform, extending distally beyond the ectocuneiform. Five well developed metatarsals are present. All metatarsals are relatively short with respect to the tarsal-metatarsal length. Mt $\mathrm{V}$ is slightly shorter than Mt III. With some variation (see Results), this pattern is also identified in non-arboreal echimyids and ctenomyids.

\subsection{2 | Tarsal-Metatarsal Pattern II (TMPII)}

In this pattern (Figure 9C,D), the tarsus is much narrower and longer than that of TMPI. The astragalus is longer than it is wide, while its head is oriented in a more parasagittal position with respect to the astragalar body. The medial tarsal bone is relatively smaller than that of the arboreal erethizontids and echimyids, contacting with the astragalomediotarsal facet of the astragalar head in a postero-plantar location. The CCJ is located distally with respect to the ANJ, resulting in a TTJ with the aspect of a broken line. The cuboid is smaller than the ectocuneiform; the latter bone is located in line with the proximodistal axis of Mt III. The plantar process of the navicular is strongly developed, extending both proximally and distally. The plantar process of the cuboid is also well developed, but not in the same extent as that of the navicular. The entocuneiform is small, a feature related to the reduction or absence of Mt I. Mt II-IV are relatively elongated and close-packed. $\mathrm{Mt} \mathrm{V}$ is reduced. This pattern typically characterizes the most cursorial cavioids but also, albeit with some variation (especially in Hydrochoerus and Cuniculus), the remaining members of this clade. Among chinchilloids, Lagostomus shows a typical TMPII but Lagidium and Chinchilla partially depart from this pattern (see Results). Finally, although they share some features with TMPI (medially located astragalar head, short navicular process of the navicular), Octodontids can also be recognized as possessing TMPII.

\subsubsection{Geometric Morphometrics and Tarsal-Metatarsal Patterns}

Several of the features that identify the two main tarsal-metatarsal patterns were analyzed in the PCA: proportions of the tarsus, orientation and obliquity of the astragalar neck, type of TTJ, and the relative size and position of the navicular, cuboid, mesocuneiform and entocuneiform (Figure 1D,E). This allowed identifying typical TMPI and TMPII, and intermediate variation based on the results of the geometric morphometrics analysis. The TMPI can be identified on the negative values of the first two PCs, and the TMPII in the positive values of these PCs. The morphological variation reflected within Octodontoidea described above (see Results) is partially in agreement with the gradient between TMPI and TMPII. The similar gradient recognized within Cavioidea varies from a typical TMPII to a modified TMPII (Hydrochoerus). Some of the morphologies that can be related with the main locomotor specializations are: typical TMPI for climbers and TMPII with a robust configuration for cursorial taxa. Diggers mostly have TMPI, with the exception of the octodontid Tympanoctomys, with a slender TMPII. The two jumpers Chinchilla and Lagidium have an intermediate morphology (between TMPI and TMPII) and the ambulatory species present a very wide range of morphologies.

\section{2 | Functional Analysis of the Tarsal Complex of Caviomorphs}

Several studies on the foot anatomy in mammals have recognized its important functional and phylogenetic implications (e.g., Argot, 2002; de Muizon et al., 1998; Gebo \& Dagosto, 1988; Lewis, 1983, 1989; Salton \& Szalay, 2004; Sargis, 2002; Szalay, 1994; Szalay \& Sargis, 2001). The tarsus supports some of the most complex loads in the body (Szalay, 1994; Szalay \& Sargis, 2001); consequently, different arrangements of the tarsal bones, reflect significant changes in the distribution of loadings and the range of movements performed by the foot. Regarding the TTJ, the ANJ reflects the degree to which the distal portion of the foot can be inverted and/or everted (Salton \& Szalay, 2004; Szalay, 1994; Szalay \& Sargis, 2001, 2006). The CCJ reflects the range of movements and force transmission from the calcaneus to the cuboid, showing either flexion-extension or the ability to rotate (pronate-supinate) this joint (Szalay, 1994; Szalay \& Sargis, 2001).

The more distal location of the CCJ with respect to the ANJ, a characteristic arrangement of TMPII (Figures 9C,D and 7A), is more efficient in cursorial and/or saltatorial locomotion, since this configuration severely restrict the mobility at the transverse ankle joint (Candela \& Picasso, 2008; Fostowicz-Frelik, 2007; Hildebrand, 1985a; Szalay, 1994; Taylor, 1976). The bones involved in both articulations are interlocked, indicating that lateral movements of the foot are limited while forwards and backwards movements are emphasized. Thus, caviomorphs having TMPII display a TTJ that restricts movements at this joint, such as in other terrestrial mammals (Fostowicz-Frelik, 2007; Hildebrand, 1985a; Szalay, 1994; Taylor, 1976).Considering the foot as a lever system (Carrano, 1997; Maynard Smith \& Savage, 1956; Stein, 2000), the resultant force (Fo) exerted by it against the ground could be augmented by increasing the in-lever arm (Li) or by increasing the magnitude the force generated by the muscles inserted onto the tuber calcanei (Fi). On the other hand, an increase of the out-lever arm (Lo) would improve speed at the expense of force. In caviomorphs with a TMPII, this later condition results from a lengthening of the distal portion of the calcaneus (a feature that places the CCJ more distally with respect to the ANJ; Candela \& Picasso, 2008), as well as from the lengthening of the metatarsals (see below), thus increasing Lo, and consequently the stride length and the speed. In chinchillids and in the octodontoids Octomys and Octodontomys, in addition to the elongation of distal portion of the calcaneus, the elongation of the tarsus is accompanied by a relative lengthening of the astragalar neck, a condition that 
could be related, at least in chinchillines, to their saltatorial locomotion (see also Ginot et. al., 2016). Thus, lengthening of the tarsal-metatarsal complex is accomplished through one or more strategies in different species. Conversely, in erethizontids and other caviomorphs having TMPI (e.g., Dactylomys), the CCJ and ANJ joints are located approximately at the same level (Figures 9A,B and 7A), a condition that allows a greater range of movements at the $\Pi \mathrm{TJ}$. The $\mathrm{CCJ}$ joint indicates the rotational abilities of the foot (Candela \& Picasso, 2008; Szalay, 1994). So, the CCJ and the ANJ of the TMPI appear to be designed to allow greater rotational movements, increasing the ability to accommodate the pes to irregular surfaces (Szalay \& Sargis, 2001; Szalay, 1994). In addition, the relatively short distal portion of the calcaneus and short metatarsals (i.e., relatively short Lo) provide a more effective Fo, albeit at a lower velocity, which would result in short, and powerful strides during locomotion.

A medially oriented astragalar head, a feature that characterizes TMPI (Figures 9A and 7A), would better assist lateral and rotational movements at the TTJ, enabling the inversion of the foot in arboreal species (Argot, 2002; Candela \& Picasso, 2008; Sargis, 2002; Szalay, 1994), so that its plantar side can be medially turned against the arboreal substrate during climbing. Medial orientation of the astragalar head is in turn related to the extensive medially extended astragalomediotarsal facet. This facet provides a broad articulation with the large medial tarsal bone, which would assist inversion of the foot. The wide contact between the astragalar head, the navicular, and the medial tarsal bone, as well as the relative enlargement of the entocuneiform, articulating with a well-developed $\mathrm{Mt} \mathrm{I}$, are features that reflect the importance of the medial region of the foot in supporting stress during climbing, while allowing lateral and rotational mobility of these tarsal bones (Argot, 2002; Candela \& Picasso, 2008; Szalay, 1994).

In erethizontids the great size of the medial tarsal bone indicates an important insertional area for the tibialis caudalis muscle, an important invertor of the pes in living porcupines (McEvoy, 1982), and possibly in other arboreal caviomorphs. The medial tarsal bone is also well developed in arboreal echimyids and Ctenomys. This condition is probably associated with the function of the tibialis caudalis muscle as an invertor and plantarflexor of the foot during climbing and digging.

A relatively large entocuneiform is also consistent with a welldeveloped area of insertion of the tibialis cranialis muscle, which in erethizontids has an important function in the inversion of the foot (McEvoy, 1982, pp. 406). In arboreal echimyids the relatively large entocuneiform could also be indicative of the significance of the tibialis cranialis muscle as an invertor during climbing. Particularly in erethizontids, the large entocuneiform, hypertrophied medial sesamoid bone, and medial orientation of $\mathrm{Mt}$ I strongly indicate a powerful grasping foot, compatible with adaptations to climbing.

The set of features of the TMPII (Figures 9C,D and 7A) of saltatorial and cursorial caviomorphs maximizes stability and facilitates planterflexion-dorsiflexion movements, as it occurs in runners/leapers of other groups of mammals (Hildebrand, 1985a). This feature, along with the small size of the medial tarsal and entocuneiform bones, and the loss of digit I all reflect the reduction of the loading support on the medial portion of the foot. The reduced size of the medial tarsal bone in the most cursorial caviomorphs, is related with the reduction of the tibialis caudalis muscle and of the very restricted ability to invert the pes. Note that in Dasyprocta the tibialis cranialis muscle would act as a dorsiflexor rather than as an invertor of the pes (García-Esponda \& Candela, 2010, 2016).

In TMPII, the relative enlargement of the ectocuneiform with respect to the cuboid indicates that the central axis of the tarsus is in line with Mt III and that it could be supporting the main load of the body (Szalay, 1994). Thus, in TMPII loading would probably be concentrated on the astragalar head-navicular-ectocuneiform-Mt III, which build the principal longitudinal axis of the foot. These features are indicative of an emphasized central region of the foot, which may support the main stress during running or leaping (Argot, 2002; Szalay, 1994).

\section{3 | Plantar Tarsal-Metatarsal Structures: Functional Considerations}

Among caviomorphs with TMPII, the most specialized cursorial cavioids (Figure 6D,F) show a different plantar anatomical pattern from that of the leaper chinchilloids Chinchilla and Lagidium (Figure 4A,B) and the ambulatory/digger Lagostomus (Figure 4C). Nevertheless, all these patterns are interpreted as adaptations to reinforce the proximal plantar region of the foot, required to run, dig and leap. In the specialized cursorials, the extended plantar process of the navicular (Figures $2 \mathrm{~A}$ and $6 \mathrm{D}, \mathrm{F})$ constitutes a buttress-like structure. This process seems to act as a strong pillar within the plantar region of the foot, strengthening the points where the tarsus withstands more thrust during the propulsion stage of the locomotor cycle. A relatively long plantar process of the navicular seems to be an adaptive feature that reaches its highest degree of expression in the cursorial Dolichotis (but see FostowiczFrelik, 2007 for a different interpretation of the degree of development of this process in Lagomorpha). The plantar region of the tarsus is also reinforced by the presence of a well-developed sesamoid bone located distally and attached to the plantar process of the cuboid (e.g., Figure 6F). In addition, the extended plantar process of the navicular seems to act as a guide for the passage of the tendons of the flexores digitorum medialis and lateralis muscles, which act as plantarflexors of the ankle joint and flexors of the joints of all digits in cavioids (García-Esponda \& Candela, 2010, 2016).

In chinchillids, the plantar process of the navicular is relatively less developed than that of the cursorial cavioids (Figures $2 B$ and $4 A, C$ ). In this case, the plantar process would not act as a buttress. Instead, the strengthening of the plantar region the tarsus is mainly accomplished by the strongly developed plantar tubercle of the Mt II, which projects toward the plantar process of the cuboid, to finally contact this bone (e.g., Figure 4C). In addition, this tubercle is distally attached or closely located to a well-developed plantar sesamoid bone. Therefore, in chinchillids the plantar tubercle of the Mt II, the well-developed plantar process of the cuboid, and the plantar sesamoid bone build a compact and strengthened anatomical unit. In Chinchilla and Lagidium this unit seems to be an adaptation to resist the impacts generated in each 
jump and to support the forces acting during the movements of the foot on the rocks. In the case of Lagostomus, the foot must resist not only the forces generated during jumping, but also those acting when the animal is digging (as for example, the recoil of the body in each movement of digging; see below).

In sum, in specialized cursorial and leaping forms, as well as in Lagostomus, the proximal plantar region of the tarsus constitutes an integrative functional unit adapted to different locomotor behaviors and substrate preferences, all of which require a strong and compact foot. These findings demonstrate multiple anatomical solutions to the same challenge (see Losos, 2011; Wainwright, 2007, and bibliography therein, for a discussion on many-to-one mapping of form to function).

The anatomical configuration of the plantar region of octodontoids and erethizontids (Figures 3 and 5), are indicative of a mobile and easily adjustable tarsus that involve a wide range of movements of the foot.

\subsection{Metatarsals: Functional Considerations}

\subsection{1 | Metatarsal length}

The elongation of the metatarsals, seen in fast-running mammals, is perhaps the feature that most entirely reflects cursoriality (e.g., Fostowicz-Frelik, 2007; Gambaryan, 1974; Hildebrand, 1985a). Such as was observed in others groups of mammals (e.g., Argot, 2002; Samuels, Meachen, \& Sakai, 2013), in cursorial caviomorphs, the lengthened metatarsals, accentuated in the Dasyproctidae Dasyprocta and Myoprocta and in the Caviidae Dolichotis and Pediolagus (Figure 2B) improve speed as well as the stride length during locomotion at the expense of force (Carrano, 1997; Maynard Smith \& Savage, 1956). On the other hand, short metatarsals in Cuniculus paca indicate that this species is not highly specialized for running or leaping habits. In Hydrochoerus the short metatarsals and low pes length index (Mt III length/femur length) are features associated with its quadrupedal paddling swimming habits (García-Esponda \& Candela, 2016).

In Chinchilla and Lagidium (Figure 2B), the lengthening of the metatarsals increases the stride length during leaping, as observed in other saltatorial mammals (Emerson, 1985). Likewise, the elongated metatarsals of the octodontoids Proechimys, Trinomys, Octodontomys, and Octomys (Figure 2B) would increase the stride length and the speed during locomotion. Thus, terrestrial echimyids and octodontids seem to parallelize the pattern observed in cursorial cavioids. The elongated metatarsals of the semiaquatic Myocastor would facilitate the length of the paddling limb, like in other hindlimb paddling semiaquatic rodents (Samuels \& Van Valkenburgh, 2008). Consequently, elongated metatarsals are present in different linages of caviomorphs that have different locomotor habits, including echimyids, octodontids, caviids, dasyproctids, and chinchillids.

In contrast, relatively short metatarsals, a feature characteristic of the highly arboreal erethizontids, and the arboreal and semifossorial echimyids (Figure 2B), would provide a more effective resultant force for locomotion, although at lower velocity, which would result in short and powerful strides.

\subsubsection{Close-Packing of the Central Metatarsals}

Another character functionally associated with leaping or cursoriality is the degree of close-packing (i.e., degree of contact) between the metatarsals. In erethizontids and arboreal echimyids, wide and not closepacked metatarsals provide room for functional interosseus muscles (Taylor, 1976), allowing independent digital movements. On the contrary, in terrestrial echimyids, leaping chinchillids and specialized cursorial dasyproctids and caviines, the close-packed metatarsals seem to increase the rigidity of the plantar sole, allowing the metatarsals to act as a single unit, a condition that would be particularly optimal during running or leaping (Argot, 2002).

\subsubsection{The Lateral and Medial Metatarsals (Mt V and Mt I)}

While variable, erethizontids and echimyids have well-developed and relatively long $\mathrm{Mt} \mathrm{I}$ and $\mathrm{Mt} \mathrm{V}$. The divergent and relatively short $\mathrm{Mt} \mathrm{I}$ of Coendou and Chaetomys emphasizes the grasping ability of their feet (McEvoy, 1982). The relative shortening of Mt I and Mt V in terrestrial echimyids with respect to those of the arboreal forms, could indicate that the central metatarsals exert the principal function in load-support during locomotion, as in cavioids.

With the exception of Cuniculus, all cavioids bear only three functional digits, concentrating the loadings on $\mathrm{Mt} \mathrm{III,} \mathrm{which} \mathrm{constitutes} \mathrm{the}$ principal axis of the foot.

The well-developed Mt V in Chinchilla and Lagidium is probably related to its function in the stabilization of the CCJ, and to emphasize the plantarflexor role of the peroneus brevis muscle, which is required for leaping (Argot, 2002). In Lagostomus, the presence of Mt V, although very reduced in length, could be reflecting its function in the stabilization of the CCJ.

\section{5 | Considerations on Digging Abilities and Foot Anatomy}

Adaptive significance of the morphological features in fossorial and subterranean rodents have been intensively investigated (e.g., Hildebrand, 1985b; Lessa, 1990; Lessa et al., 2008; Morgan \& Verzi, 2011; Stein, 2000; and bibliography therein). In general, it is recognized that the highly digging species show marked modifications, such as the acquirement of shorter and thicker extremities than related epigeous species, with the consequent mechanical advantages proportioned by shorter lever arms.

Here, we discuss the anatomy of the foot of caviomorphs that display different degrees of fossoriality and digging abilities (sensu Lessa et al., 2008): Ctenomys, Tympanoctomys, Octodontomys, Octomys, Euryzygomatomys, Clyomys, and Lagostomus.

All Ctenomys species have a subterranean style of life (i.e., they spent most of their life underground and have the ability to construct complex burrows; Lessa et al., 2008). As expected, adaptations for subterranean life in Ctenomys appear to be reflected in their foot anatomy, which is characterized by short robust metatarsals (Figure 2B) and a marked stepped metatarsal pattern (i.e., Mt III is longer than Mt IV, and the latter is longer than Mt V; Figure 5F). As observed in the hand (Morgan \& Verzi, 2011), the main axis of the foot of Ctenomys (Figure 
$5 F$ ) is concentrated onto Mt III (mesaxony), which would act bracing the body against the backward forces generated during digging. In addition to their strengthened metatarsals, the tarsal features of Ctenomys (Figures $5 \mathrm{~F}$ and $8 \mathrm{~A}$ ) are compatible with a relatively wide ability of movements (e.g., ANJ and CCJ located at the same level, plantar process of the navicular scarcely developed, astragalar head somewhat medially orientated).

Among Octodontidae, Tympanoctomys species construct complex burrow systems with several branches and openings (Lessa et al., 2008; Patton et al., 2015). The foot anatomy of Tympanoctomys (Figure 5I) does not show any anatomical modification that is functionally related to digging, apart from its relatively short metatarsals (Figure 2B). Thus, in agreement with previously established observations (Lessa et al., 2008), the construction of complex burrows does not appear to require substantial morphological modifications of the foot.

Octodontomys gliroides is able to dig simple burrows (Lessa et al., 2008). This taxon can be classified as a fossorial species because individuals spend a substantial fraction of their life outside their burrows (Lessa et al., 2008). In agreement with previous studies that indicate that this species has no obvious morphological adaptations for a fossorial life style (Lessa et al., 2008), the foot of O. gliroides does not have any feature that can be functionally related to digging. The tarsus of $O$. gliroides (Figures $5 \mathrm{H}$ and $8 \mathrm{~A}$ ) with the $\mathrm{CCJ}$ distally located with respect to $\mathrm{ANJ}$, gracile, relatively long (Figure $2 \mathrm{~B}$ ) and not close-packed metatarsals (Figure $5 \mathrm{H}$ ), and with Mt IV slightly longer than Mt III (paraxony), suggest a stable tarsal-metatarsal complex at the TTJ, but being able to agile movements. The relatively well developed cuboid and its alignment with Mt IV, suggest that the main forces generated during locomotion would be uniformly distributed, through both rays III and IV. These features would allow the foot to acquire medial and lateral postures to accommodate their anatomical structures to irregular surfaces, typical of rocky environments.

Octomys mimax is a saxicolous and surface dwelling species with digging ability (Lessa et al. 2008; Patton et al., 2015). According to previous authors there is no evidence that this species modifies daytime resting sites through digging and its activity was associated with the utilization of simple burrows (Lessa et al., 2008). The foot of Octomys mimax has no features related to digging. Its long, delicate and not closely-packed metatarsals (Figures 2B and 5G) are in agreement with rapid and agile movements. Gracile bones reduce the inertia of the limb, increasing rotational velocity and thus stride rate (Gambaryan, 1974; Hildebrand, 1985a; Samuels et al., 2013). As noted for O. gliroides, the set of features of $0 . \operatorname{mimax}$ (indicate a stable $\Pi \mathrm{TJ}$ and agile movements of the metatarsals to accommodate the foot to irregular surfaces and move on rocky environments.

The semifossorial echimyids Euryzygomatomys and Clyomys diffe from Ctenomys by having a more robust tarsus and a relatively larger ectocuneiform, which is more parasagittally oriented with respect to Mt III (Figures 5D and 8A). The metatarsals are relatively shorter and more robust than those of the terrestrial Proechimys showing a stepped pattern, but to a lesser degree than in Ctenomys (Figure 2B). These features would provide an advantage to resist the forces generated during digging (such as was inferred for the carpal-metacarpal features of these genera; Morgan \& Verzi, 2011).

Finally, the chinchillid Lagostomus maximus has tarsal-metatarsal features (Figures $2 \mathrm{~B}$ and $4 \mathrm{C}$ ) related to restricted movements. The closely-packed metatarsals would constitute a functional unit, which is more compact than that of the digging octodontoids and saltatorial chinchillines. This pattern seems to be an adaptation to resist the forces generated during digging, acting as a strong and secure support to anchor firmly in the substrate.

\section{5 | INTEGRATIVE ANALYSIS AND CONCLUSIONS}

\section{$5.1 \mid$ Adaptations and Phylogeny}

According to our results, there is substantial anatomical variation of the caviomorph foot that reflects their diverse locomotor behaviors. Morphological variation also seems to include a strong phylogenetic influence at different taxonomic levels. As noted above, we recognized two distinct tarsal-metatarsal patterns, which represent the extremes of this anatomical variation (Figure 7), one present in arboreal erethizontids and echimyids (TMPI; Figures 7A,B and 8), and the other in the most specialized cursorial cavioids (TMPII; Figures $7 C, D$ and 8 ). The remaining caviomorph species display intermediate tarsal-metatarsal arrangements, but can also be assigned to one of these two patterns.

Erethizontoids have the typical TMPI, characterized by a highly mobile tarsal-metatarsal complex adapted to climb, showing some distinctive features (very large medial sesamoid, Mt I medially oriented,) that are not identified in other superfamilies. The foot of the different species of porcupines examined displays an essentially similar morphology that is congruent with their homogenous locomotor ecology.

Among octodontoids, a gradient of morphological variation from Echimyidae to Octodontidae was observed (Figure 8A). Echimyids fit in TMPI (Figures 9B and 8A), but display some intrafamilial morphological disparity (Figure 8A). The arboreal forms (Kannabateomys, Makalata, Dactylomys, Phyllomys, Lonchotrix) have a typical TMPI, similar to that of erethizontids, whereas the terrestrial (Trinomys, Proechimys), the semifossorial (Euryzygomatomys, Clyomys), and the semiaquatic (Myocastor) taxa are characterized by a more robust tarsus. In turn, arboreal and semifossorial forms are characterized by short and robust metatarsals, whereas those of terrestrial and semiaquatic taxa are more elongated. Some of the differences observed between arboreal and terrestrial echimyids (e.g., robustness of the tarsus, the interlocking of the bones, the metatarsal length, and the relative size of the cuboid) are comparable, although to a lesser degree, to those observed between the highly arboreal erethizontoids and the most specialized cursorials cavioids (Figures 7 and 8A). The morphological variation observed within echimyids may be interpreted as functional, with their dissimilar tarsal-metatarsal complex reflecting their different locomotor habits. Beyond this variation, the anatomy of the echimyid foot does not deviate noticeably from the TMPI; so that it can be interpreted as constrained by phylogeny. The tarsal-metatarsal complex of the subterranean Ctenomyidae shares several features with that of echimyids, 
possessing essentially a TMPI (Figure 7), but with some specializations (such as relatively more robust metatarsals and mesaxony), that are interpreted as adaptations to dig. Octodontids mainly differ from echimyids and Ctenomys by having a more elongated and narrow tarsalmetatarsal complex, displaying a gracile TMPII (Figure 7 and 8A). In turn, within octodontids, the fossorial Tympanoctomys has shorter metatarsals than the surface dwelling Octodontomys and the saxicolous Octomys. In sum, Octodontoids show a broad range of tarsalmetatarsal morphologies in agreement with their diverse locomotor habits. This morphological variation could be explained both as a product of different locomotor adaptations as well as a result of the phylogenetic effect at the family level (Figure 8A).

Cavioids share a robust TMPII (Figure 7 and $8 \mathrm{~A}$ ), characterized by features that are compatible with cursorial habits. Nevertheless, as noted above, a gradient of morphological variation is detected between the semiaquatic Hydrochoerus, the ambulatory Cuniculus, and the remaining cavioids (Figure 8A). The cursorial Dolichotis, Pediolagus, Dasyprocta and Myoprocta have a typical TMPII, with features that are interpreted as adaptations to run. This morphology departs further from that of the generalized Cuniculus paca, an ambulatory species without specializations to run, which displays a configuration that "anticipates" the specialized tarsal-metatarsal pattern of the typical cursorial species. On the other hand, Hydrochoerus is the cavioid with the most robust tarsus and relatively shortest metatarsals; features that are interpreted as adaptations to swim (García-Esponda \& Candela, 2016). The anatomical variation observed within Cavioidea facilitates different locomotor behaviors, but maintains a distinctive cavioid tarsalmetatarsal complex. The phylogenetic signal evident here may point to cavioids being ancestrally cursorial with later divergence in the semiaquatic Hydrochoerus.

Chinchilloids exhibit a marked variation when comparing the saltatorial Lagidium and Chinchilla to Lagostomus. The latter genus shows a typical TMPII, while the former have a rather intermediate morphology between TMPI and TMPII (Figures 7 and $8 \mathrm{~A}$ ). This variation can be interpreted as the result of different adaptations to jump and dig, respectively, but also it could be explained by phylogenetic effects.

Therefore, the diverse tarsal-metatarsal morphologies detected between the main clades of caviomorphs reflect their diverse locomotor habits regardless of their different evolutionary histories (Figure 8B). Furthermore, our study indicated similar morphological trends of the tarsal-metatarsal complex in distantly related species that display similar locomotor habits. For example, all cursorial taxa, including Dasyprocta and Myoprocta (Dasyproctidae), Dolichotis and Pediologus (Caviidae), and even the ambulatory Trinomys and Proechimys (Echimyidae), display elongation of the metatarsals (Figure 2B). Similarly, fossorial octodontoids, belonging to three different families (Echimyidae, Ctenomyidae and Octodontidae) have short and robust metatarsals. So, as noted in other mammals (e.g., Muñoz, Cassini, Candela, \& Vizcaíno, 2017; Samuels et al., 2013), within and between different superfamilies of caviomorphs, species with similar locomotor habits display similar tarsal-metatarsal features as a result of convergent evolution, despite their distinct evolutionary histories.
We also observed species with different locomotor habits, but sharing a similar morphology of some features. For example, the cursorial Dolichotis (Caviidae), the semiaquatic Myocastor (Echimyidae), and the saltatorial Chinchilla (Chinchillidae) are all characterized by an elongated pes (Figure 2B). This suggests, at least for this feature, the existence of morphological convergence of different locomotor behaviors. This can be an example of multiple selective advantages of a single trait (e.g., Losos, 2011), as the same morphological adaptation can be functionally important for different ecologies. While elongation of the pes increases stride length and length of the out lever in cursorial and jumping taxa, it functions to increase the size of the paddling limb in semiaquatic taxa (Emerson, 1985; Hildebrand, 1985a; Samuels \& Van Valkenburgh, 2008). Nevertheless, other tarsal-metatarsal characters of these same taxa are very different between them (for example the width of tarsus, the type of TTJ, and the relative size of cuboid), which could be indicative of a phylogenetic effect or that different functional requirements are acting on the morphological traits.

Finally, we observed different morphologies of the tarsalmetatarsal complex in species with similar locomotor habits, as seen in the semiaquatic Hydrochoerus and Myocastor. As most semiaquatic rodents (Howell, 1930), Myocastor has elongated metatarsals and uses pelvic paddling as the main mode of swimming (Samuels \& Van Valkenburgh, 2008). In contrast, the capybara is characterized by a quadrupedal paddling mode of swimming, displaying relatively robust and short metatarsals. In agreement with these different modes of swimming, Myocastor and Hydrochoerus show dissimilar tarsal-metatarsal morphologies that are interpreted as different adaptations for a similar style of life (another example of many-to-one mapping of form to function, see Wainwright, 2007; Losos, 2011). Semiaquatic caviomorphs add to those mammalian species that show different structural solutions to similar environmental challenges (Hildebrand, 1985a,b; Samuels et al., 2013; Stein, 2000).

Likewise, among those caviomorphs with digging abilities, different tarsal-metatarsal patterns were identified: Euryzygomatomys, Clyomys, and Ctenomys show different versions of TMPI, whereas Tympanoctomys and Lagostomus have different configurations of TMPII. These differences can be interpreted as reflecting different adaptations to dig as well as the presence of phylogenetic signal at different taxonomic levels.

We conclude that the variation observed in the tarsal-metatarsal patterns of caviomorphs can be explained by function-based hypotheses expressing specific adaptations, but within its particular phylogenetic context.

\subsection{The Usefulness of Tarsal Characters in Cladistic Analyses}

An essential aspect that arises from our study is the lack of independence of certain tarsal-metatarsal characters. Because the tarsus is a complex multi-bone system, constituted by coadapted bones, it is expected that a change in some of their elements involves a modification of the tarsal-metatarsal complex as a whole, within the coupled system (Salton \& Szalay, 2004; Szalay, 1994; Szalay \& Sargis, 2001). So, 
for example, the position of the sustentaculum of the calcaneus in relation to the calcaneo-cuboid facet is detected as a nonindependent feature with respect to the relative position of the $\mathrm{CCJ}$ and ANJ. Other nonindependent tarsal characters are: orientation of the astragalar head, which is related to relative size of the medial tarsal bone and with a degree of plantar contact with that bone; the relative robustness of the ectocuneiform, which is related to relative size of the cuboid; relative size of the entocuneiform, which is related to the degree of contact with the medial tarsal bone, as well as with the degree of development of $\mathrm{Mt} \mathrm{I}$ and digit I; the degree of close-packing of the metatarsals, which is related to the degree of development of $\mathrm{Mt} \mathrm{I}$ and $\mathrm{Mt} \mathrm{V}$, as well as with the degree of elongation of Mt II-IV.

However, the tarsus is not necessarily considered as the sum of numerous characters or only as one complex trait (Szalay, 1994). As was indicated by Szalay (1994, pp. 112), the system "...changes in such ways that while the elements making them up are coadapted, the components are capable of somewhat independent evolutionary change within the complex." We identified that the plantar structures, the reduction and close-packing of metatarsals and the robustness of specific tarsal bones change in different ways according to the taxonomic group and the locomotor specializations. Thus, the tarsal-metatarsal complex can be recognized as a functional-adaptive system of interrelated characters, but in which some elements are able to change individually. Under this perspective the foot structures will be useful as reliable independent characters for cladistic analyses of caviomorphs.

\section{ACKNOWLEDGMENTS}

We gratefully thank D. Voglino (MPS-Z), J.A. de Oliveira (MN), D Verzi, and I. Olivares (MLP), D. Flores and P. Teta (MACN), U Pardiñas (CNP), R. Ojeda (IADIZA), D. Romero (MMPMa), E. Westwig (AMNH), K. Zyskowski (YPM), and E. Lorenzen (ZMUC) for facilitating access to specimens under their care. We specially thank $M$. Ercoli and C. Robinet for facilitating several photos of specimens of caviomorphs and D. Voglino for his decisive assistance in several aspects of this work. Special thanks to J.X. Samuels and another anonymous reviewer and J.M. Starck for their suggestions and comments which improve an earlier version of our manuscript.

\section{REFERENCES}

Abello, M. A., Candela, A. M. (2010). Postcranial skeleton of the Miocene marsupial Palaeothentes (Paucituberculata, Palaeothentidae): Paleobiology and phylogeny. Journal of Vertebrate Paleontology, 30, 1515-1527.

Antoine, P. -O., Marivaux, L., Croft, D. A., Billet, G., Ganerød, M., Jaramillo, C., ... Salas Gismondi, R. (2012). Middle Eocene rodents from Peruvian Amazonia reveal the pattern and timing of caviomorph origins and biogeography. Proceedings - Royal Society of Edinburgh. Section B: Biology, 279, 1319-1326.

Argot, C. (2002). Functional-adaptive analysis of the hindlimb anatomy of extant marsupials and the paleobiology of the Paleocene marsupials Mayulestes ferox and Pucadelphis andinus. Journal of Morphology, 253, 76-108.

Candela, A. M., \& Picasso, M. B. J. (2008). Functional anatomy of the limbs of Erethizontidae (Rodentia, Caviomorpha): Indicators of locomotor behavior in Miocene porcupines. Journal of Morphology, 269, 552-593.
Candela, A. M., Rasia, L. L., \& Pérez, M. E. (2012). Paleobiology of Santacrucian Caviomorph rodents: A morpho-functional approach. In S. F. Vizcaíno, R. F. Kay, \& M. S. Bargo (Eds.), Early Miocene paleobiology in Patagonia: High-latitude paleocommunities of the Santa Cruz Formation (pp. 289-305). Cambridge: Cambridge University Press.

Carrano, M. T. (1997). Morphological indicators of foot posture in mammals: A statistical and biomechanical analysis. Zoological Journal of Linnean Society, 127, 77-104.

de Muizon, C., Cifelli, R. L., \& Bergqvist, L. P. (1998). Eutherian tarsals from the early Paleocene of Bolivia. Journal of Vertebrate Paleontology, 18, 655-663.

Elissamburu, A., \& Vizcaíno, S. F. (2004). Limb proportions and adaptations in caviomorph rodents (Rodentia: Caviomorpha). Journal of Zoology, 262, 145-159.

Ellerman, J. R. (1940). The families and genera of living rodents. Vol I: Rodents other than Muridae (pp. 689). London: British Museum (Natural History).

Emerson, S. B. (1985). Jumping and leaping. In M. Hildebrand, D. M. Bramble, K. F. Liem, D. B. Wake (Eds.), Functional Vertebrate Morphology (pp. 58-72). Cambridge: Harvard University Press.

Fabre, P. -H., Hautier, L., Dimitrov, D., \& Douzery, E. J. P. (2012). A glimpse on the pattern of rodent diversification: A phylogenetic approach. BMC Evolutionary Biology 12, 88.

Fabre, P. -H., Hautier, L., \& Douzery, E. J. P. (2015). A synopsis of rodent molecular phylogenetics, systematics, and biogeography. In P. Cox, \& L. Hautier (Eds.), Evolution of the rodents-Advances in phylogeny, functional morphology and development (pp. 19-69). Cambridge: Cambridge University Press.

Flores, D. A. (2009). Phylogenetic analyses of postcranial skeletal morphology in didelphid marsupials. Bulletin of the American Museum of Natural History, 320, 1-81.

Fostowicz-Frelik, L. (2007). The hind limb skeleton and cursorial adaptations of the Plio-Pleistocene rabbit Hypolagus beremendensis. Acta Palaeontologica Polonica, 52, 447-476.

Gambaryan, P. P. (1974). How mammals run: Anatomical adaptations (pp. 368). New York: John Wiley and Sons.

García-Esponda, C. M., \& Candela, A. M. (2010). Anatomy of the hindlimb musculature in the cursorial caviomorph Dasyprocta azarae Lichtenstein, 1823 (Rodentia, Dasyproctidae): Functional and evolutionary significance. Mammalia, 74, 407-422.

García-Esponda, C. M., \& Candela, A. M. (2016). Hindlimb musculature of the largest living rodent Hydrochoerus hydrochaeris (Caviomorpha): Adaptations to semiaquatic and terrestrial styles of life. Journal of Morphology, 277, 286-305.

Gebo, D. L., \& Dagosto, M. (1988). Foot anatomy, climbing, and the origin of the Indriidae. Journal of Human Evolution, 17, 135-154.

Gebo, D. L., Dagosto, M., Beard, K. C., \& Qi, T. (2001). Middle Eocene primate tarsals from China: Implications for haplorhine evolution. American Journal of Physical Anthropology, 116, 83-107.

Ginot, S., Hautier, L., Marivaux, L., \& Vianey-Liaud, M. (2016). Ecomorphological analysis of the astragalo-calcaneal complex in rodents and inferences of locomotor behabiours in extinct rodent species. Peer 4, e2393. DOI 10.7717/peerj.2393

Hildebrand, M. (1978). Insertions and functions of certain flexor muscles in the hind leg of rodents. Journal of Morphology, 155, 11-122.

Hildebrand, M. (1985a). Walking and running. In M. Hildebrand, D. M. Bramble, K. F. Liem, \& D. B. Wake (Eds.), Functional Vertebrate Morphology (pp. 38-57). Cambridge: Harvard University Press.

Hildebrand, M. (1985b). Digging of quadrupeds. In M. Hildebrand, D. M. Bramble, K. F. Liem, \& D. B. Wake (Eds.), Functional vertebrate morphology (pp. 89-109). Cambridge: Harvard University Press. 
Horovitz, I., Sánchez-Villagra, M. R., Martin, T., \& Aguilera, O. A. (2006). The fossil record of Phoberomys pattersoni Mones 1980 (Mammalia, Rodentia) from Urumaco (Late Miocene, Venezuela), with an analysis of its phylogenetic relationships. Journal of Systemic Palaeontology, 4, 293-306.

Howell, A. B. (1930). Aquatic mammals: Their adaptations to live in water (pp. 338). Springfield: Charles C Thomas Publisher.

Klingenberg, C. P. (2011). MorphoJ: An integrated software package for geometric morphometrics. Molecular Ecology Resources, 11, 353-357.

Lessa, E. P. (1990). Morphological evolution of subterranean mammals: Integrating structural, functional and ecological perspectives. In E. Nevo, \& O. A. Reig (Eds.), Evolution of Subterranean Mammals at the Organismal and Molecular Level (pp. 211-230). New York: Wiley-Liss.

Lessa, E. P., Vassallo, A. I., Verzi, D. H., \& Mora, M. S. (2008). Evolution of morphological adaptations for digging in living and extinct ctenomyid and octodontid rodents. Biological Journal of Linnean Society London, 95, 267-283.

Lewis, O. J. (1980a). The joints of the evolving foot. Part I. The ankle joint. Journal of Anatomy, 130, 527-543.

Lewis, O. J. (1980b). The joints of the evolving foot. Part II. The intrinsic joints. Journal of Anatomy, 130, 833-857.

Lewis, O. J. (1983). The evolutionary emergence and refinement of the mammalian pattern of foot architecture. Journal of Anatomy, 137, 21-45.

Lewis, O. J. (1989). Functional morphology of the evolving hand and foot (pp. 368). New York, NY: Oxford University Press.

Losos, J. B. (2011). Convergence, adaptation, and constraint. Evolution, $65,1825-1840$.

Manly, B. F. (1994). Multivariate statistical methods: A primer (pp. 215). London: Chapman and Hall.

Mares, M. A., \& Ojeda, R. A. (1982). Patterns of diversity and adaptation in South American Hystricognath rodents. In M. A. Mares, \& H. H. Genoways (Eds.), Mammalian biology in South America (pp. 393-432). Special Publication Series No. 6. Pennsylvania: Pymatuning Laboratory of Ecology, University of Pittsburgh.

Maynard Smith, J. M., \& Savage, R. J. G. (1956). Some locomotory adaptations in mammals. Zoological Journal of Linnean Society, 42, 603622.

McEvoy, J. S. (1982). Comparative myology of the pectoral and pelvic appendages of the North American porcupine (Erethizon dorsatum) and the prehensile-tailed porcupine (Coendou prehensilis). Bulletin of the American Museum of Natural History, 173, 337-421.

Morgan, C. C. (2009). Geometric morphometrics of the scapula of South American caviomorph rodents (Rodentia: Hystricognathi): Form, function and phylogeny. Mammalian Biology, 74, 497-506.

Morgan, C. C., \& Verzi, D. H. (2011). Carpal-metacarpal specialisations for burrowing in South American octodontoid rodents. Journal of Anatomy, 219, 167-175.

Muñoz, N. A., Cassini, G. H., Candela, A. M., \& Vizcaíno, S. F. (2017). Ulnar articular surface 3-D landmarks and ecomorphology of small mammals: a case of study in two Early Miocene typotheres (Notoungulata) from Patagonia. Earth and Environmental Science Transactions of Royal Society of Edinburgh, 106, 315-323.

Nowak, R. M. (1991). Walker's mammals of the world (pp. 1629). Baltimore and London: The John Hopkins University Press.

Ojeda, R. A., Novillo, A., \& Ojeda, A. A. (2015). Large-scaled richness patterns, biogeography and ecological diversification in caviomorph rodents. In A. I. Vasallo, \& D. Antenucci (Eds.), Biology of caviomorph rodents: Diversity and evolution (pp. 121-138). Buenos Aires: SAREM (Sociedad Argentina para el Estudio de los Mamíferos).
Patton, J. L., Pardiñas, U. F. J., \& D'Elía G. (2015). Mammals of South America. Vol. 2. Rodents (pp. 1336). Chicago: The University of Chicago Press.

Prochel, J., Begall, S., \& Burda, H. (2014). Morphology of the carpal region in some rodents with special emphasis on hystricognaths. Acta Zoology, 95, 220-238.

R Development Core Team. (2015). R: A language and environment for statistical computing. Vienna: R Foundation for Statistical Computing.

Rocha-Barbosa, O, Youlatos, D., Gasc, J. P., \& Renous, S. (2002). The clavicular region of some cursorial Cavioidea (Rodentia: Mammalia). Mammalia 66, 413-421.

Rocha-Barbosa, O., Loguercio, M. F. C., Renous, S., \& Gasc, J. P. (2005). Limb joints kinematics and their relation to increasing speed in the guinea pig Cavia porcellus (Mammalia: Rodentia). Journal of Zoology, 266, 293-305.

Rohlf, F. J. (1990). Rotational fit (Procrustes) methods. In F. L. Bookstein, \& F. J. Rohlf (Eds.), Proceedings of the Michigan morphometrics workshop (pp. 227-236). Ann Arbor: University of Michigan Museums.

Rohlf, F. J. (2015). The tps series of software. Hystrix, 26, 9-12.

Salton, J. A., \& Szalay, F. S. (2004). The tarsal complex of Afro-Malagasy Tenrecoidea: a search for phylogenetically meaningful characters. Journal of Mammalian Evolution, 11, 73-104.

Samuels, J. X., \& Van Valkenburgh, B. (2008). Skeletal indicators of locomotor adaptations in living and extinct rodents. Journal of Morphology, 269, 1387-1411.

Samuels, J. X., Meachen, J. A., \& Sakai, S. A. (2013). Postcranial morphology and the locomotor habits of living and extinct Carnivorans. Journal of Morphology, 274, 121-146.

Sargis, E. J. (2002). Functional morphology of the hindlimb of tupaiids (Mammalia, Scandentia) and its phylogenetic implications. Journal of Morphology, 254, 149-185.

Schneider, C. A., Rasband, W. S., \& Eliceiri, K. W. (2012). NIH Image to ImageJ: 25 years of image analysis. Nature Methods 9, 671-675.

Stein, B. R. (2000). Morphology of subterranean rodents. In A. E. Lacey, J. L. Patton, \& G. N. Cameron (Eds.), Life underground. The biology of subterranean rodents (pp. 19-61). Chicago: The University of Chicago Press.

Szalay, F. S. (1994). Evolutionary history of the marsupials and an analysis of osteological characters (pp. 481). Cambridge: Cambridge University Press.

Szalay, F. S., \& Decker, R. L. (1974). Origins, evolution, and function of the tarsus in late Cretaceous eutherians and Paleocene primates. In F. A. Jenkins, Jr. (Ed.), Primate locomotion (pp. 223-254). New York: Academic Press.

Szalay, F. S., \& Sargis, E. J. (2001). Model-based analysis of postcranial osteology of marsupials from the Palaeocene of Itaboraí (Brazil) and the phylogenetics and biogeography of Metatheria. Geodiversitas, 23, 139-302.

Szalay, F. S., \& Sargis, E. J. (2006). Cretaceous therian tarsals and the metatherian-eutherian dichotomy. Journal of Mammalian Evolution, 13, 171-210.

Taylor, M. E. (1976). The functional anatomy of the hindlimb of some African Viverridae (Carnivora). Journal of Morphology, 148, 227-254.

Upham, N. S., \& Patterson, B. D. (2015). Phylogeny and evolution of caviomorph rodents: a complete timetree for living genera. In A. I. Vassallo, \& D. Antenucci (Eds.), Biology of caviomorph rodents: Diversity and evolution (pp. 63-120). Buenos Aires: Sociedad Argentina para el Estudio de los Mamíferos (SAREM).

Voloch, C. M., Vilela, J. F., Loss-Oliveira, L., \& Schrago, C. G. (2013). Phylogeny and chronology of the major lineages of New World hystricognath rodents: Insights on the biogeography of the Eocene/Oligocene arrival of mammals in South America. BMC Research Notes, 6, 160. 
Weisbecker, V., \& Schmid, S. (2007). Autopodial skeletal diversity in hystricognath rodents: Functional and phylogenetic aspects. Mammalian Biology, 72, 27-44.

Woods, C. A., \& Kilpatrick, C. W. (2005). Infraorder hystricognathi brandt, 1855. In D. E. Wilson, \& D. M. Reeder (Eds.), Mammal species of the world (pp. 1538-1600). Baltimore: Johns Hopkins University Press.

How to cite this article: Candela AM, Muñoz NA, GarcíaEsponda CM. The tarsal-metatarsal complex of caviomorph rodents: Anatomy and functional-adaptive analysis. Journal of Morphology. 2017;00:000-000. https://doi.org/10.1002/jmor. 20678

\section{APPENDIX: LIST OF CAVIOMORPH SPECI- MENS EXAMINED (WITH TARSUS OR PART OF TARSUS PRESERVED) (NUMBER OF SPECIMENS IN BRACKETS)}

Specimens examined are housed in the following collections: MLP, Museo de La Plata (La Plata, Argentina); CNP, Colección de Mamíferos del Centro Nacional Patagónico (Puerto Madryn, Argentina); IADIZA CM, Colección Mastozoológica del Instituto Argentino de Investigaciones de Zonas Áridas (Mendoza, Argentina); CML, Colección Mamíferos Lillo (San Miguel de Tucumán, Argentina); MACN, Museo Argentino de Ciencias Naturales "Bernardino Rivadavia" (Buenos Aires, Argentina); MMPMa, Museo Municipal de Ciencias Naturales "Lorenzo Scaglia" (Mar del Plata, Argentina); MPS-Z, Museo de Ciencias Naturales "P. Antonio Scasso" (San Nicolás, Argentina); MN; Museu Nacional (Rio de Janeiro, Brazil); AMNH, American Museum of Natural History (New York, USA), FMNH, Field Museum (Chicago, USA); YPM, Yale Peabody Museum of Natural History (New Heaven, USA); Zoological Museum University of Copenhagen (ZMUC).

\section{Erethizontoidea}

\section{Erehtizontidae}

- Erethizon dorsatum (1) MLP1086

- Coendou prehensilis (5) MN 4923, MN 4925, MN 4936, MN 34186, MLP 1084

- C. spinosus (1) MPS-Z 185

- C. insidiosus (2) MN 46936, MLP 18.VII.97.2

- Chaetomys subspinosus (2) MN 9680, MN 46250

\section{Cavioidea}

\section{Cuniculidae}

- Cuniculus paca (6) MN 60557, MN 1682, MN 4878, MN 4871, MN 8476, MACN 49.396

\section{Dasyproctidae}

- Dasyprocta azarae (8) CNP 896, CNP 790, MN 4848, MN 4852, MN 1854, MN 4859, MN 4961, MN 134185.

- Myoprocta acouchi (2) YPM 1360, AMNH 130148

\section{Caviidae}

\section{Caviinae}

- Cavia aperea (10) MLP 15-II-96-49, MLP 29.XII.00.15, MLP 585.3, MLP 585.4, MLP 5.VI.00.8, MLP 30.V.02.7, MLP 15.II.96.49, MLP 2. IV.02.9, MLP 11.VIII.99.54, MPS-Z 203-206.

- Microcavia australis (7) MLP 26.VII.01.21, MLP 26.VII.01.22, MLP 7. IV.99.7, MACN 34.7, MACN 40.53, CNP 1033, CNP 276,

- Microcavia sp. (2) MACN 36.36, MPS-Z 2014

- Galea leucoblephara (=G. musteloides) (4) MACN 28-141, MLP 1928, MLP 1929, CNP 1470

\section{Dolichotinae}

- Dolichotis patagonum (8) MLP 208, MLP 252, MLP 250, MLP 642, MLP 236, MLP 249, MLP 275, MPS-Z 186

- Pediolagus salinicola (4) MACN 30.388, MLP 1081, MPS-Z 197, MPS-Z 198

\section{Hydrochoerinae}

Hydrochoerus hydrochaeris (7) MACN 43.43, MACN 31.18, MACN 14.038, MPS-Z 141, MPS-Z 142, MPS-Z 143, MPS-Z 188

\section{Chinchilloidea}

\section{Chinchillidae}

Chinchillinae.

- Chinchilla sp. (5) MACN 13037, MACN 26116, MACN 39390, MACN 45.11, MLP 31.XII.02.37

- Lagidium viscacia (3) MPS-Z 199, MLP 20.21, MACN 44.25

\section{Lagostominae}

- Lagostomus maximus (7) MACN 48.85, MLP 1083, MLP 27.IV.95.1, MPS-Z 200, MLP 15.V.96.3, MACN 23.14, MACN 21983

\section{Octodontoidea}

\section{Octodontidae}

- Octomys mimax (1) IADIZA CM 03785

- Octodontomys gliroides (2) CNP 651, MACN 25.197

- Tympanoctomys kirchnerorum (1) CNP 1819

- T. aureus (1) CML 4136 


\section{Ctenomyidae}

- Ctenomys sp. (2) MPS-Z 201, CNP UP 3609

- C. talarum (1) MLP 2507

- C. australis (1) MLP 7.XI.95.7

- C. magellanicus (1) CNP UP 3599

\section{Echimyidae}

- Myocastor coypus (5) MLP 1172, MPS-Z 202, MPS-Z 213, MACN, MMPMa 28

- Phyllomys pattoni (1) MN 33515
- Makalata didelphoides (2) AMNH 97324, FMNH 62051

- Proechimys guairae (=Proechimys poliopus) (1) MLP 22.II.00.7

- P. steerei (1) FMNH 55403

- Trinomys dimidiatus (3) MN 48010, MN 31370, MN 31426

- Euryzygomatomys spinosus (2) MN 31351, MLP 16.VII.02.11

- Clyomys laticeps (1) ZMUC L77

- Lonchothrix emiliae (1) AMNH 94866

- Dactylomys dactylinus (1) YPM 1391

- Kannabateomys amblyonyx (2) FMNH 94340, MN 1961

- Olallamys albicaudus (1) FMNH 71130 